\title{
Abnormal storm waves in the winter East/Japan Sea: generation process and hindcasting using an atmosphere-wind wave modelling system
}

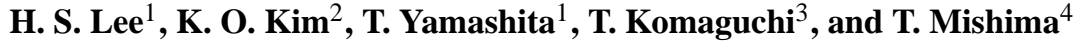 \\ ${ }^{1}$ Graduate School for International Development and Cooperation, Hiroshima University, Higashi-Hiroshima, Japan \\ ${ }^{2}$ Korea Ocean Research \& Development Institute, Ansan, Korea \\ ${ }^{3}$ Blue Wave Institute of Technology Co., Ltd, Tokyo, Japan \\ ${ }^{4}$ Blue Wave Institute of Technology Co., Ltd, Higashi-Hiroshima, Japan
}

Received: 3 August 2009 - Revised: 7 April 2010 - Accepted: 12 April 2010 - Published: 15 April 2010

\begin{abstract}
Abnormal storm waves cause coastal disasters along the coasts of Korean Peninsula and Japan in the East/Japan Sea (EJS) in winter, arising due to developed low pressures during the East Asia winter monsoon. The generation of these abnormal storm waves during rough sea states were studied and hindcast using an atmosphere-wave coupled modelling system. Wind waves and swell due to developed low pressures were found to be the main components of abnormal storm waves. The meteorological conditions that generate these waves are classified into three patterns based on past literature that describes historical events as well as on numerical modelling. In hindcasting the abnormal storm waves, a bogussing scheme originally designed to simulate a tropical storm in a mesoscale meteorological model was introduced into the modelling system to enhance the resolution of developed low pressures. The modelling results with a bogussing scheme showed improvements in terms of resolved low pressure, surface wind field, and wave characteristics obtained with the wind field as an input.
\end{abstract}

\section{Introduction}

The surface winds over the East/Japan Sea (EJS) vary distinctively with the seasons, blowing mild or moderate and variable in summer and very strong due to the East Asian monsoon and storms in winter. In winter atmospheric low pressures reacting with and passing through the EJS can sometimes cause abnormal storm waves on the Korean and Japanese coasts of the EJS.

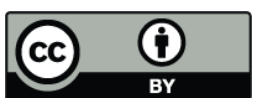

Correspondence to: $\mathrm{H}$. S. Lee (lee.hansoo@gmail.com)
In February 2008, abnormal storm waves due to a developed atmospheric low pressure system propagating from the west off Hokkaido, Japan, to the south and southwest throughout the EJS caused extensive damage along the central coast of Japan on the EJS side and along the east coast of Korea. The accompanying high waves were mainly swells that developed with sufficient fetch over the EJS and lasted more than a day (Lee et al., 2008). The observed maximum wave heights and periods along the central coast of Japan are described in Table 1, while the observed maximum wave height and peak wave period at Anmok on the central east coast of Korea were $5.5 \mathrm{~m}$ and 14.17 s at 11:00:00 UTC on 24 February 2008. During February of that year, the abnormal storm waves at Toyama Bay, which are called "Yorimawari Waves" in Japan, caused some of the most severe coastal damage ever induced by such conditions.

Many studies have examined the generation process and prediction of abnormal storm waves in the EJS. Some of the studies have been conducted in Japan, such as those described below. According to Kitaide (1952), the Yorimawari Waves in Toyama Bay are long-period wind waves or swell generated due to the strong north and northeasterly winds formed by a quasi-stationary developed atmospheric low-pressure area. Isozaki (1971) and Isozaki and Yoshio (1972) studied the characteristics of Yorimawari Waves and described their predictability based on meteorological observations and weather charts of past events. Yoshida et al. (1985) numerically studied an event of abnormal storm waves in the EJS using a simple spectral wave model based on an energy balance equation and showed that the wave heights were predictable to some extent, whereas the wave periods were not well coordinated with observations. Yamaguchi et al. (1994) estimated extreme wave

Published by Copernicus Publications on behalf of the European Geosciences Union. 
Table 1. Observed maximum values of wave characteristics in February 2008 (from Nationwide Ocean Wave information network for Port and HArbourS (NOWPHAS) of The Port and Airport Research Institute (PARI), Japan).

\begin{tabular}{lccl}
\hline Stations & Wave height $(\mathrm{m})$ & Period $(\mathrm{s})$ & Date and Time \\
\hline Naoetsu & 6.40 & 10.2 & 10:00:00 UTC 23 February 2008 \\
Toyama & 9.92 & 16.2 & 07:00:00 UTC 24 February 2008 \\
Fushiki Toyama & 4.22 & 14.2 & 05:00:00 UTC 24 February 2008 \\
Wajima & 7.73 & 13.2 & 03:00:00 UTC 24 February 2008 \\
\hline
\end{tabular}

heights including Yorimawari Waves in the EJS by statistical analysis of a number of wave hindcasting data obtained from spectral wave model simulations. In one study, Hatada and Yamaguchi (1998) suggested a method to predict the abnormal storm waves quantitatively as they propagated toward the central coast of Japan in the EJS using a precise wave ray method and a shallow water prediction model. Recently, third-generation spectral wave models have been widely used to estimate wave characteristics not only in the EJS but in other seas as well.

In Korea, Choi and Joung (1979) studied abnormal storm waves that occurred in October 1976 using Wilson's method of forcing by gradient wind and showed that the significant wave heights agreed fairly well with observations, while the corresponding wave periods needed to be improved. The wind field created by an extratropical cyclone was called a twister in their study. Joung et al. (1984) studied the generation mechanism of a low-pressure system developed over the EJS on 2 January 1981 by analysing available data and using results from an adiabatic inviscid quasi-geostrophic model. To simulate meteorological conditions realistically, the authors considered required physical mechanisms such as a cold air outbreak, the topographical effects of the Korean Peninsula, and a mesoscale convective complex. Jeong et al. (2007) studied abnormal storm waves of October 2006 based on wave and wind observations and found that the abnormal storm waves were a consequence of strong wind waves that propagated over swell to the east coast of Korea at the same time. Kim and Lee (2008) also studied the same abnormally high waves of October 2006 as well as those of October 2005 using a third-generation spectral wave model, SWAN, and showed that the results from numerical simulation were not satisfactory compared to observations. One of the principal explanations proposed for their results was inaccurate wind forcing, imposed after linear interpolation of the simulation results from Regional Data Assimilation and Prediction System (RDAPS) of Korean Meteorological Agency (KMA).

Summarising the literature, abnormal storm waves in the EJS are mainly due to swells propagating from the west off Hokkaido caused by quasi-stationary developed atmospheric low pressures located to the east of or near Hokkaido, which can be categorised as an extratropical cyclone. When this swell is propagated to the coasts around the EJS, either simultaneously or consecutively accompanied by strong wind waves created by a tornado, abnormal storm waves are observed along the coasts and can cause damage or even disaster. The recent abnormal storm waves on 24 February 2008 and related coastal damage in Anmok, Korea, and in Toyama Bay, Japan, were typical of the phenomenon.

However, these previous studies lack information either on meteorological conditions or on wave fields. The meteorological conditions of a wind field of the cited papers were simply represented by interpolating the observations or coarse spatial grid data to a computing grid without considering the topographical effects, and the wave field is described without considering the bathymetric effects on propagating waves in numerical studies. According to Cavaleri and Bertotti $(2004,2006)$ and Ponce de León and Guedes Soares (2008), unlike the open ocean where wind field data are generally good, the wind field in an enclosed basin such as the Mediterranean Sea is almost always underestimated, mainly because of the orography of the surrounding land. The bias of the wind field depends on the proximity of land, and the wave fields obtained from the wind field input through a series of numerical experiments showed an average underestimate of almost $30 \%$ to $40 \%$ as compared to the recorded data. This showed the crucial importance of the wind field in wave field estimation, especially in terms of the resolution of the wind field and the effect of the surrounding land. The semi-enclosed EJS has very similar characteristics to those of the Mediterranean Sea, being surrounded by the mountainous land of Russia and the Korean Peninsula to the north and west and by the islands of Japan to the south and east. Therefore, it is indispensable to analyse the meteorological conditions through mesoscale meteorological modelling to best understand and estimate abnormal storm waves in numerical studies. More recently, Lee et al. (2008) studied the mechanisms of generation of abnormal storm waves, including Yorimawari Wave events, in the EJS in February 2008. The study was based on observations and numerical simulations using an atmosphere-wave modelling system, taking into account meteorological conditions as well as topographical and bathymetric effects in numerical studies. Mase et al. (2008) also performed forecasting and hindcasting of Yorimawari Waves in February 2008 using a mesoscale meteorological 
model and a third-generation spectral wave model. Moreover, Yamashita et al. (2009) studied the possibility of more intense and frequent occurrence of extratropical cyclones in La Niña (i.e., a forthcoming warm phase in terms of Pacific Decadal Oscillation) periods in the north-west Pacific, considering climate change based on historical climate indices.

Since the abnormal storm waves are a key factor not only in coastal damage and disaster, but also in the design of coastal structures, it is critical to estimate these waves accurately, taking into account the meteorological conditions and topographical and bathymetric effects. Therefore, the objectives of this study are to improve wave field estimation using an atmosphere-wave coupled modelling system by introducing a bogussing scheme to resolve the developed low pressure correctly and to study the generation mechanisms and characteristics of abnormal storm waves in the EJS in terms of meteorological conditions and numerical simulations.

This paper consists of six sections, as follows: In Sect. 2, the atmosphere-wave modelling system is described briefly. In Sect. 3, the bogussing scheme and its effects on meteorological modelling in the case of abnormal storm waves in December 2003 are described. The applications of the modelling system to two additional events, in February 1991 and February 2008, are described in Sect. 4. Discussions of the bogussing scheme and meteorological conditions for the abnormal storm waves are presented in Sect. 5, which is followed by a summary and conclusions in Sect. 6 .

\section{Atmosphere-wave modelling system}

\subsection{Mesoscale meteorological model}

The meteorological model in an atmosphere-wave modelling system is a three-dimensional non-hydrostatic mesoscale model, MM5, developed at Pennsylvania State University (PSU)-National Center for Atmospheric Research (NCAR). This model is based on non-hydrostatic, compressible form of governing equations in spherical and sigma coordinates with physical processes such as precipitation physics, Planetary Boundary Layer (PBL) processes and atmospheric radiation processes incorporated by a number of physics parameterisations. MM5 also considers the complex topographical effects during the calculation. For more details on MM5, refer to Grell et al. (1995).

\subsection{Wind wave model}

The third generation wave model WaveWatchIII (WW3) was used in this study. The WW3 is based on the energy balance equation and simulates wave propagation through geographic, frequency and directional space. The wave refraction, diffraction and shoaling due to spatial variances in water depth and currents are considered in WW3 simulation. Wave generation by wind input $\left(S_{\text {in }}\right)$, energy dissipation by whitecapping $\left(S_{\mathrm{ds}}\right)$ and bottom friction $\left(S_{\mathrm{bot}}\right)$ and non-linear wave-wave interactions $\left(S_{\mathrm{nl}}\right)$ are taken into account in the energy balance equation for source and sink terms. With the calculation of the energy balance equation in WW3, the twodimensional directional spectrum, $F(k, \theta)$, as well as the further action density spectrum $N(k, \theta) \equiv F(k, \theta) / \omega$, can be obtained. Then, after integrating the two-dimensional spectrum over directions, an one-dimensional spectrum, $F(k)$, can be generated, whereas total variation or wave energy, $E$, can be obtained by integrating over the whole spectrum. For more details of WW3 v2.22 used in this study, the interested reader is referred to Tolman (2002). The parameterisation of wave generation by wind input using the source term package by Tolman and Chalikov (1996) is described in the following paragraph. The frequency increment factor $\left(X_{\omega}\right)$, first frequency $\left(\omega_{0}\right)$, number of frequencies and directions for all simulations in the wave model were set to $1.1,0.0412 \mathrm{~Hz}, 25$ and 24 , respectively.

How the energy is transferred from atmosphere to waves is of importance in an atmosphere-wave coupled modelling system. In WW3, the wind-wave interaction parameter, $\beta$, is introduced and approximated using the non-dimensional apparent wave frequency, $\tilde{\omega}_{\mathrm{a}}$ and drag coefficient, $C_{\lambda}$. The surface drag coefficient and the actual wind input source term, $S_{\text {in }}$, to waves are a function of the two way interactions between atmosphere and waves and are calculated by iterative computation (Chalikov and Belevich, 1993; Chalikov, 1995).

\section{Depression bogussing}

The available global meteorological data from atmospheric general circulation models (AGCMs) are used for short-term (hours or a few days), medium-range (up to 10 days), and seasonal forecasts and also for long-term climatic purposes. Depending on the range, AGCMs are coupled to different models for waves or ocean circulation. However, extreme weather events such as tropical cyclones, typhoons, hurricanes and gales, as simulated by global AGCMs, are not appropriate for simulation of abnormal storm waves and extreme wave analysis. This is due to the coarse resolution of temporal and spatial dimensions in these models (see Table 2). For example, the global dataset of Japan Meteorological Agency's Grid Point Values (JMA GPV) shows only $60 \%$ to $70 \%$ of the magnitude of the observed wind speed (Fig. 5). Therefore, we introduced a bogussing scheme to improve our estimation of meteorological conditions such as wind and pressure field, which are the main driving forces of abnormal storm waves in the EJS, by resolving the developed low pressure more accurately in a mesoscale model. The bogussing scheme was first developed to improve the numerical simulation of tropical cyclones in a mesoscale model (LowNam and Davis, 2001); details are in Appendix A. 
Table 2. Examples of freely available global meteorological dataset for background data of mesoscale model.

\begin{tabular}{|c|c|c|c|c|}
\hline Dataset & $\begin{array}{l}\text { Spatial } \\
\text { resolution }\end{array}$ & $\begin{array}{l}\text { Temporal } \\
\text { resolution }\end{array}$ & Available period & Available site for dataset \\
\hline NCEP GFL & 1.0 degree & $6 \mathrm{~h}$ & nowcast and forecast data & http://nomads.ncep.noaa.gov/ \\
\hline NCEP FNL & 1.0 degree & $6 \mathrm{~h}$ & July 1999 to present & http://dss.ucar.edu/datasets/ds083.2/ \\
\hline NCEP NCAR & & & 1948 to February 2009 & http://dss.ucar.edu/pub/reanalysis/ \\
\hline ECMWF ERA40 & 2.5 degree & $6 \mathrm{~h}$ & mid-1957 to mid-2002 & http://data-portal.ecmwf.int/data/d/era40_daily/ \\
\hline ECMWF ERA15 & 2.5 degree & $6 \mathrm{~h}$ & December 1978 to February 1994 & http://data-portal.ecmwf.int/data/d/era15 \\
\hline GSM of JMA GPV & 1.25 degree & $6 \mathrm{~h}$ & January 2005 to present & http://gpvjma.omni.hpcc.jp/ gpvjma/index.html \\
\hline JMA JRA-25 & 1.25 degree & $6 \mathrm{~h}$ & January 1979 to December 2004 & http://jra.kishou.go.jp/JRA-25/index_en.html \\
\hline
\end{tabular}

\subsection{Effect of depression bogussing}

As first guess, the bogussing scheme was performed on a wide range of grids in first guess to ensure that storms were completely removed from the background in the global model. If storms and vortices are not completely removed in the background data, the bogussing scheme generates a new storm or vortex wind over the background data. Therefore, there would be two or more storms and vortices in the initial state of the meteorological model run. For evaluation of the effect of a bogussing scheme on a low-pressure system, the method was applied to abnormal storm events in December 2003, which had observed maximum wave heights of about $13 \mathrm{~m}$ at Naoetsu and caused coastal damage along the central coast of Japan on the EJS side.

For all applications in this study, high-resolution Blackadar PBL scheme (Blackadar, 1979), Reisner's graupel moisture scheme (Reisner et al., 1998) and Grell cumulus scheme (Grell, 1993) were used because of the grid resolutions of $27 \mathrm{~km}$ for domain 1 and $9 \mathrm{~km}$ for domain 2 . Fourdimensional data assimilation (FDDA) (Stauffer and Seaman, 1990) was applied to the first and second domains in wind, temperature and mixing ratio fields. The other details of model configuration such as set-up of domains and initial and background data are described in their respective application subsections below.

\subsection{Event in December 2003}

\subsubsection{Data}

The meteorological conditions during the abnormal storm waves are shown in weather charts every twelve hours from 00:00:00 UTC 19 December to 12:00:00 UTC 20 December 2003 (Fig. 1). An atmospheric low-pressure system with a minimum of $1000 \mathrm{hPa}$ developed near Korean Peninsula was moving towards the east over the EJS at 00:00:00 UTC 19 December. Subsequently, this low-pressure system rapidly strengthened within a day in its central pressure from $1000 \mathrm{hPa}$ to $972 \mathrm{hPa}$ at 00:00:00 UTC 20 December while staying east off Aomori Prefecture for more than $12 \mathrm{~h}$. Dur- ing this movement, another atmospheric low-pressure system of $996 \mathrm{hPa}$ was developing south of Hokkaido. This weaker low-pressure system also retained its strength for more than $12 \mathrm{~h}$. During this development and the quasi-stationary states of two low-pressure zones, the winds were consistently blowing southward from the north and northeast. The observed winds at Ogata Wave Observatory (OWO) of Kyoto University ranged from 18 to $22 \mathrm{~m} / \mathrm{s}$ at 06:00:00 UTC 20 December 2003 (Fig. 5a).

The bogussing scheme was applied to the two atmospheric low-pressure systems in Fig. 1, one with the lowest central pressure of $992 \mathrm{hPa}$, the maximum tangential wind $\left(V_{\max }\right)$ of $30 \mathrm{~m} / \mathrm{s}$, and the maximum radii $\left(R_{\mathrm{m}}\right)$ of $90 \mathrm{~km}$ located in the EJS near the Aomori Prefecture, and the other with $972 \mathrm{hPa}, 40 \mathrm{~m} / \mathrm{s}$, and $300 \mathrm{~km}$ located in the Pacific Ocean at 00:00:00 UTC 20 December 2003. These information of positions and estimated maximum wind speeds and pressures were obtained from the JMA weather chart. The area of background data used for the bogussing scheme was in a $22 \times 22$ grids range of Global Spectral Model (GSM) data, because the search radius was fixed to $400 \mathrm{~km}$ and the radius of maximum wind speed was $90 \mathrm{~km}$ due to the resolution of GSM data. The Rankine vortex was used for wind profiles of the vortices.

Numerical simulations for this study had been conducted for conditions of abnormal storm waves observed at Naoetsu Harbour, Nigata Prefecture, Japan, at 07:00:00 UTC 20 December in 2003. The recorded maximum and significant wave heights were $12.93 \mathrm{~m}$ and $9.24 \mathrm{~m}$, respectively and the corresponding wave periods were $16.8 \mathrm{~s}$ and $12.9 \mathrm{~s}$, respectively (Fig. 2). The abnormal high waves were also observed at OWO; however, the observed wave heights at OWO were limited and not credible because the water depth of measurement site at OWO was $7 \mathrm{~m}$ within a range of surf zone in rough sea.

\subsubsection{Model set-up}

The simulations of the meteorological model were conducted by nesting two domains. The domain D1 (with $27 \mathrm{~km}$ grid intervals) covers the whole EJS and a part of the Pacific Ocean, 
(a)

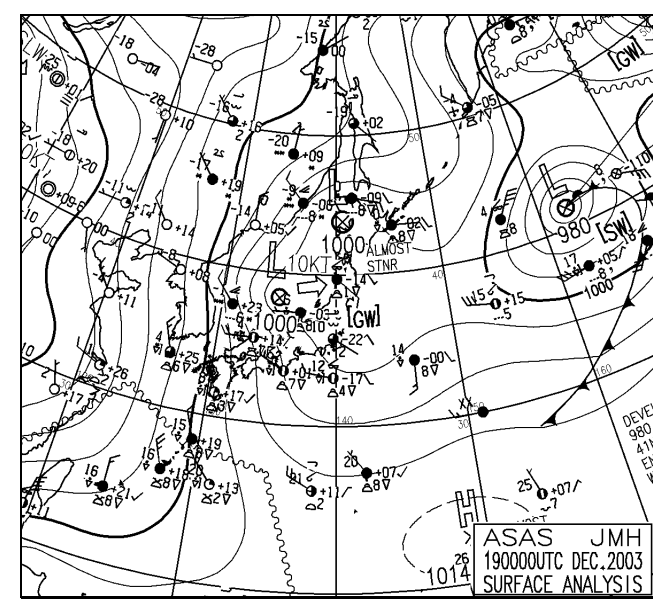

(c)

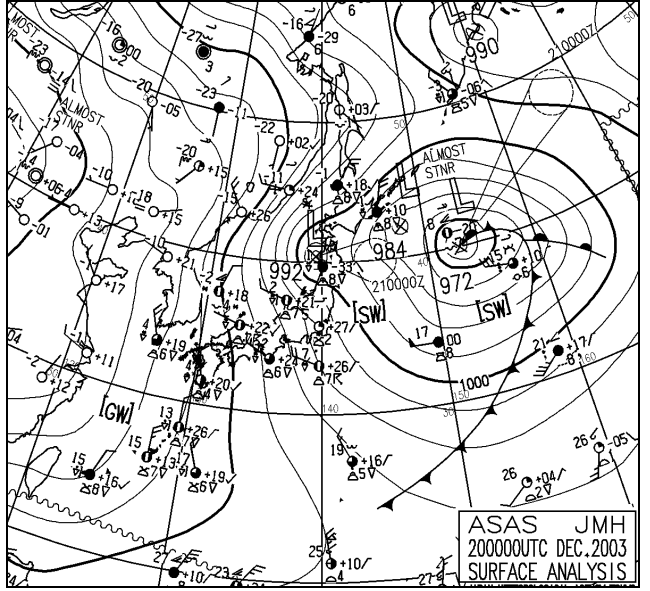

(b)

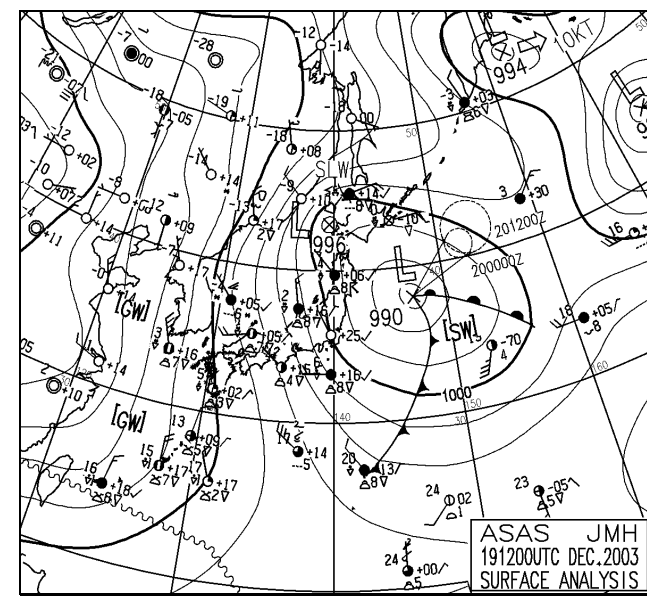

(d)

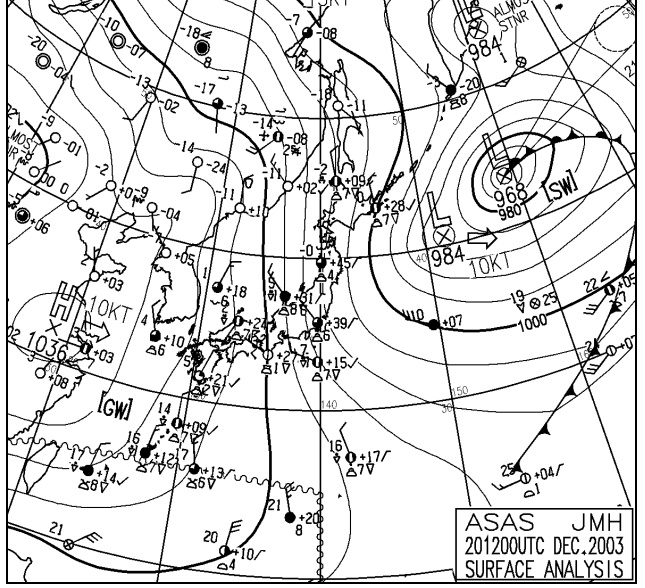

Fig. 1. Weather charts for $12 \mathrm{~h}$ increments from 00:00 UTC 19 December to 12:00 UTC 20 December 2003 (from JMA).

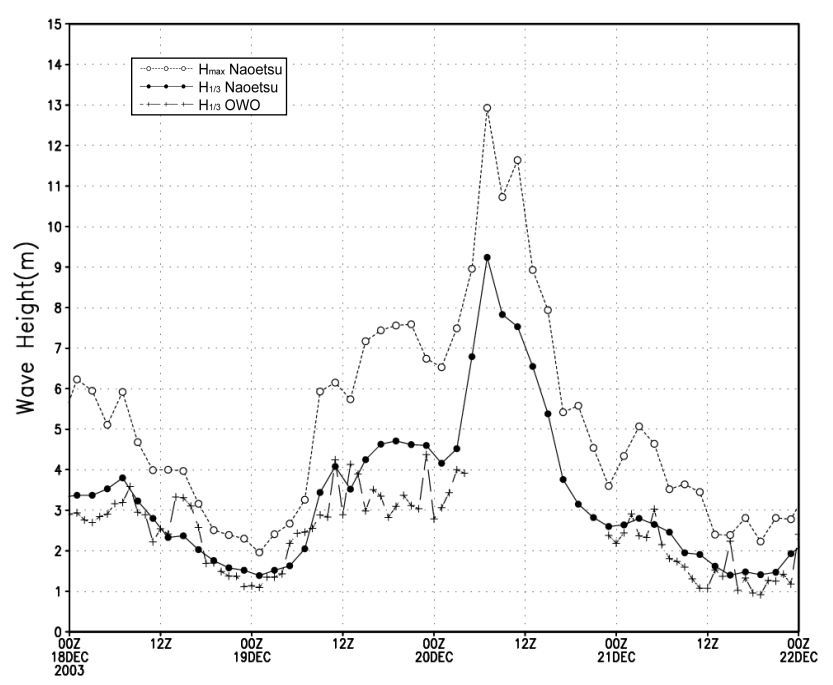

Fig. 2. Observed maximum wave height (o) and significant wave height $(\bullet)$ at Naoetsu and significant wave height $(+)$ from the Ogata Wave Observatory (OWO) of Kyoto University. including both low-pressure systems (Fig. 3), whereas the domain D2 (with $9 \mathrm{~km}$ intervals) covers only the EJS and includes one of the developed lows located to the west of Aomori Prefecture. In addition, twenty-three vertical sigma layers from the surface up to $100 \mathrm{hPa}$ level for both domains 2 and 3 plus $60 \times 69$ horizontal grids for domain 2 were set up for MM5 simulation with a $60 \mathrm{~s}$ time step. Computation of MM5 was carried out for six days from 00:00:00 UTC 17 to 00:00:00 UTC 23 December in 2003 with Real-time Global sea surface temperature (RTG_SST) data (Gemmill et al., 2007).

Numerical simulations of wave model were performed for the two domains corresponding to those of MM5 with water depth taken from a general bathymetric chart of the oceans (Monahan, 2008) for domain 1 and $1 \mathrm{~min}$ regional digital bathymetry (Choi et al., 2002) for domain 2 . The lateral and surface boundary conditions for the meteorological model were imposed every six hours from the GSM of JMA GPV dataset (Table 2). Three numerical computations were made under various conditions as shown in Table 3. 


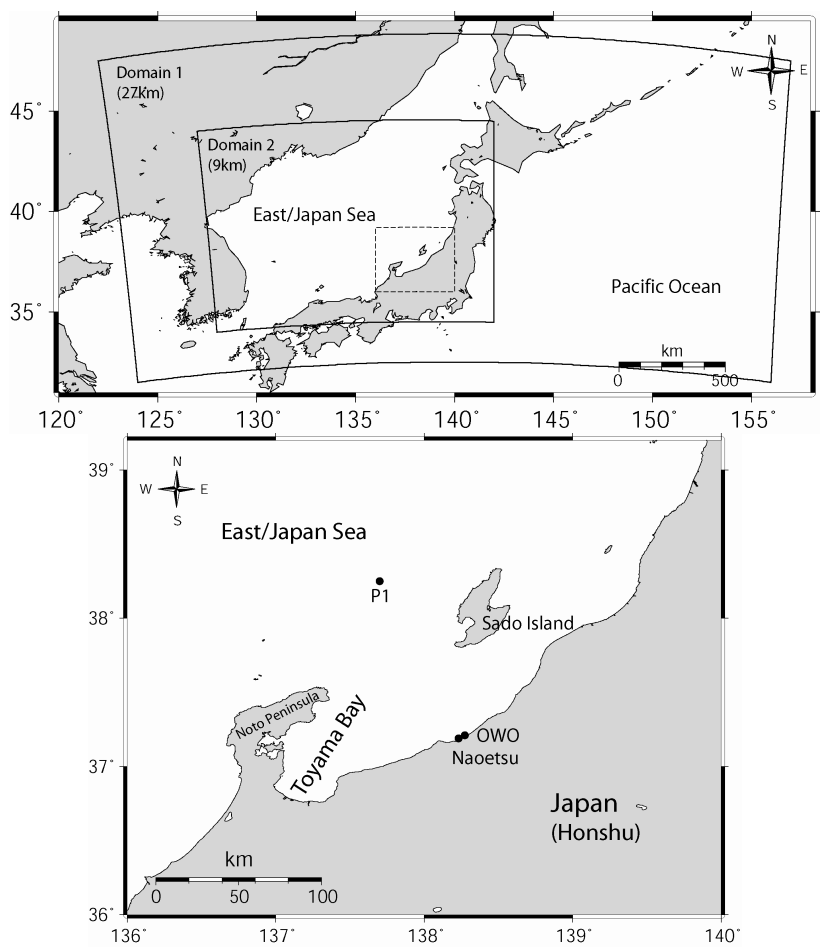

Fig. 3. Computational domains of the mesoscale model for the event of December 2003 and locations of OWO of Kyoto University, Naoetsu Harbour, and P1 (a point off Sado Island).

Table 3. Simulation conditions of WW3 for the event of December 2003.

\begin{tabular}{llll}
\hline Case & Domain & $\begin{array}{l}\text { Initial and lateral } \\
\text { boundary condition }\end{array}$ & $\begin{array}{l}\text { Bogussing } \\
\text { scheme }\end{array}$ \\
\hline D1 & Domain1 $(27 \mathrm{~km})$ & JMA GSM $(6 \mathrm{~h} \mathrm{int})$ & No \\
D1-TB & Domain1 $(27 \mathrm{~km})$ & JMA GSM $(6 \mathrm{~h} \mathrm{int})$ & Applied \\
D2-TB & Domain2 $(9 \mathrm{~km})$ & D1-TB results & Applied \\
\hline
\end{tabular}

\subsubsection{Simulation results}

Figure 4 shows the sea level pressure distribution of GSM data and simulation results of three simulation cases. The two atmospheric lows of GSM data were resolved, but somewhat weaker than those in the JMA weather chart. The result of the D1 case did not show good resolution for the two lows, whereas with the bogussing scheme applied, the D1-TB and D2-TB cases yielded better results for sea level pressure distribution, resolving the area of low pressure well.

The observed time-series data of wind speed at $10 \mathrm{~m}$ above sea surface at OWO and computed time-series data of three simulation cases at Naoetsu are compared in Fig. 5a. The observed and computed time-series data of significant wave (a)

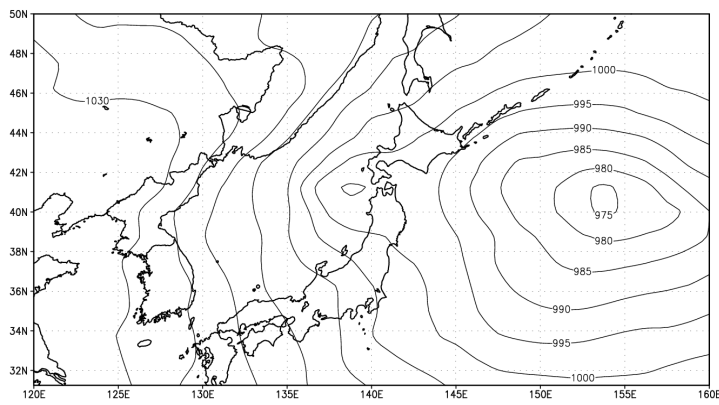

(b)

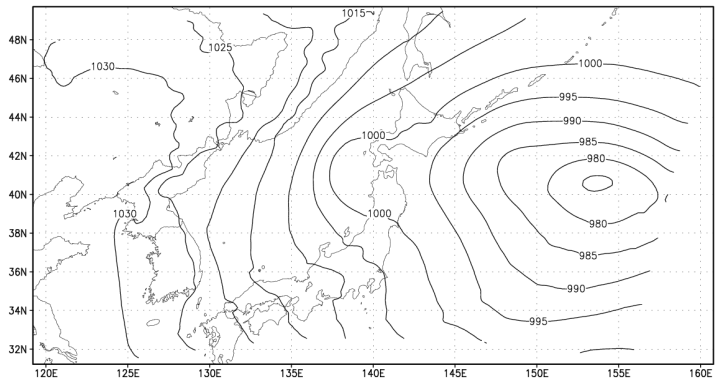

(c)

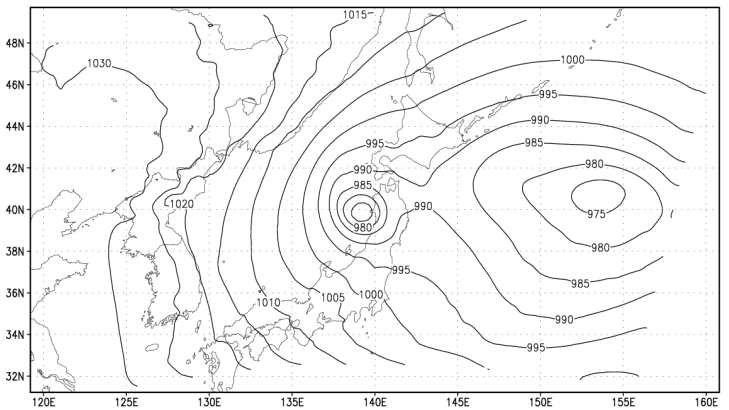

(d)

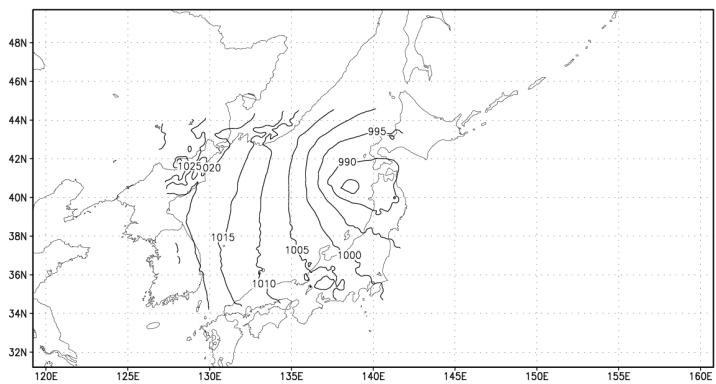

Fig. 4. Sea level pressure of (a) the operational GSM of the JMA GPV, (b) D1 case, (c) D1-TB case, and (d) D2-TB case at 00:00 UTC 20 December 2003.

heights at Naoetsu and P1 (see Fig. 3 for the location of P1) are shown in Fig. 5b and c, respectively. Comparison of the significant wave periods between observed and computed values is presented in Fig. 5d. The simulation results in Fig. $5 \mathrm{~b}$ to $\mathrm{d}$ show that the bogussing scheme obviously intensifies the maximum wind speed, hence also the significant wave height. The peaks of wind speed, wave height and wave period were improved after applying the bogussing scheme. The results of sea level pressure from the nested domain 2 in 

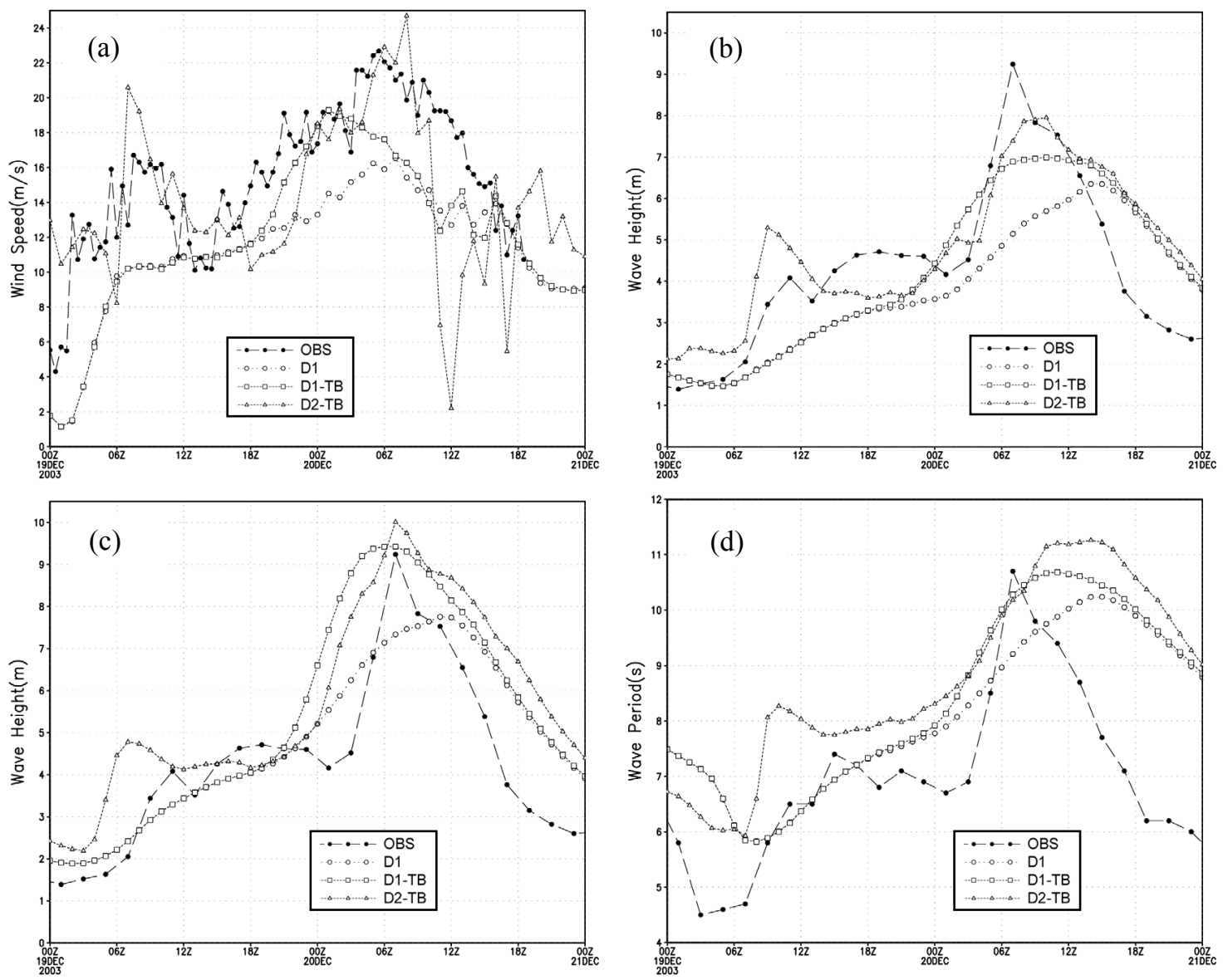

Fig. 5. Comparisons between observed and computed values from the abnormal storm wave event in December 2003. (a) Observed (propeller anemometer) $U_{10}$ wind speed at OWO and computed (D1, D1-TB, D2-TB cases) wind speed at Naoetsu, (b) observed (JMA) and computed (D1, D1-TB, D2-TB cases) significant wave heights at Naoetsu, (c) observed (JMA) and computed (D1, D1-TB, D2-TB cases) significant wave heights at P1 (see Fig. 4 for its location), and (d) observed (JMA) and computed (D1, D1-TB, D2-TB cases) significant wave periods at Naoetsu.

Fig. 4 are higher than the GSM data and D1 case, and they reproduce the changes of wind speed patterns as shown in Fig. 5a. The significant wave height at Naoetsu was somewhat underestimated in all the cases. The best agreement among them is provided by the D2-TB case. In Fig. 5b and c, when compared to the other cases, the significant wave heights of the D1 case show a time delay of about six hours. The simulation results of the D1 case using GSM data in Fig. $5 \mathrm{~b}$ to $d$ show that neither the reproduction of the wind fields nor the hindcasting of abnormal storm waves using the modelled wind data were accurate. This is primarily due to the coarse spatial and temporal resolution of the global background data.

\section{Hindcasts of abnormal storm waves}

Two additional simulations of abnormal storm waves, in February 1991 and February 2008, were performed to investigate the generation process and the characteristics of abnormal storm waves in the EJS. The two events caused coastal damage along the east coast of Korea and the central coast of Japan in the EJS. These two events were selected because the abnormal storm waves in February 2008 caused some of the most severe coastal damage ever recorded, and fairly good observations were made during the event, whereas the waves in February 1991 caused less coastal damage, although higher values of wave characteristics were observed than in the 2008 event. The observed data, model configuration and the results are described in the following subsections. 
(a)

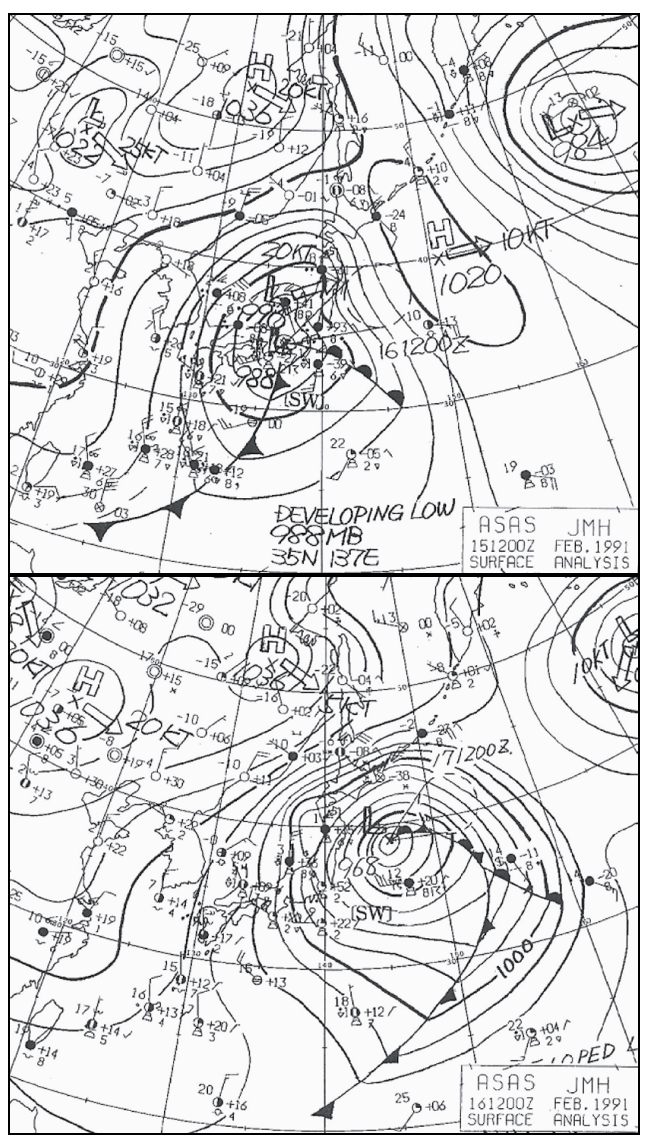

(b)

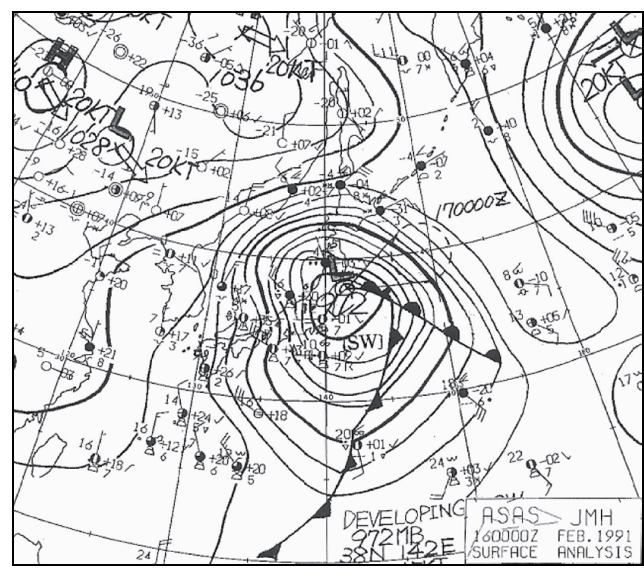

(d)

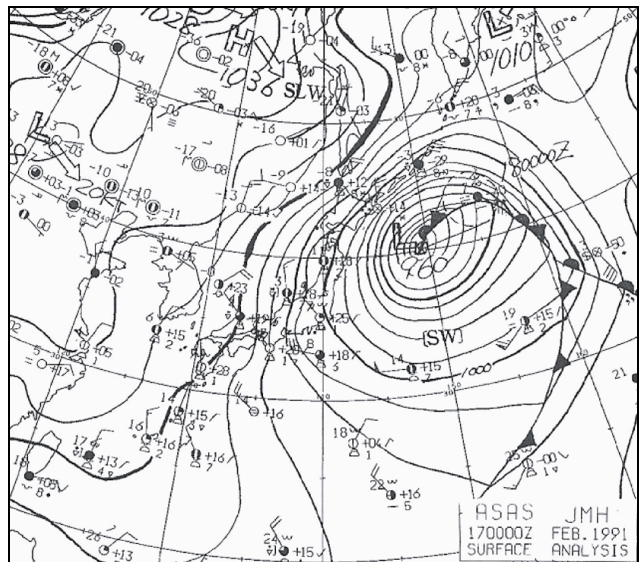

Fig. 6. Weather charts for twelve hour increments from 12:00 UTC 15 February to 00:00 UTC 17 February 1991 (from JMA).

\subsection{Event in February 1991}

\subsubsection{Data}

The meteorological conditions during the abnormal storm waves in February 1991 are presented in Fig. 6. An area of low pressure was well developed to the west of Kyushu, Japan, in the East China Sea at 00:00:00 UTC 14 February 1991 and moved slowly eastward. While the low pressure area was moving eastward, another low-pressure system developed very nearby, and the two systems strengthened, with a central pressure dropping to $990 \mathrm{hPa}$ and $988 \mathrm{hPa}$, respectively, at 12:00:00 UTC 15 February 1991. Then the two low-pressure systems merged into one developed lowpressure system while moving northeast over Honshu, Japan. When the low-pressure system approached the area east of Aomori, it kept its quasi-stationary state and strengthened continuously as its central pressure dropped to $960 \mathrm{hPa}$ at 00:00:00 UTC 17 February 1991.

\subsubsection{Model set-up}

Figure 7 shows the computational domains for the meteorological and wave models. A four-level nesting was performed throughout the simulations with grid intervals of $36 \mathrm{~km}, 12 \mathrm{~km}, 4 \mathrm{~km}$, and $1.333 \mathrm{~km}$ for each domain both in atmosphere and in wave modelling. The largest domain covers the entire Korean Peninsula, Japan, the EJS, and parts of the north-west Pacific Ocean, allowing correct simulation of the large-scale meteorological features while reducing the boundary effects on the focus area.

In the case of the event of February 1991, simulations were performed with three different background conditions from the freely available global dataset to investigate the characteristics of the dataset. The three simulations were performed and the datasets used for background data for meteorological model were the ECMWF 40 Year Re-analysis (ERA40), the Japanese 25-year Reanalysis (JRA-25), and the National Centers for Environmental Prediction (NCEP) NCAR datasets (Table 2). FDDA was applied to the first domain in the wind, temperature and mixing ratio fields every six hours with the corresponding background data for all simulations. The duration of the simulation was six days from 00:00:00 UTC 13 to 00:00:00 UTC 19 February 1991. 

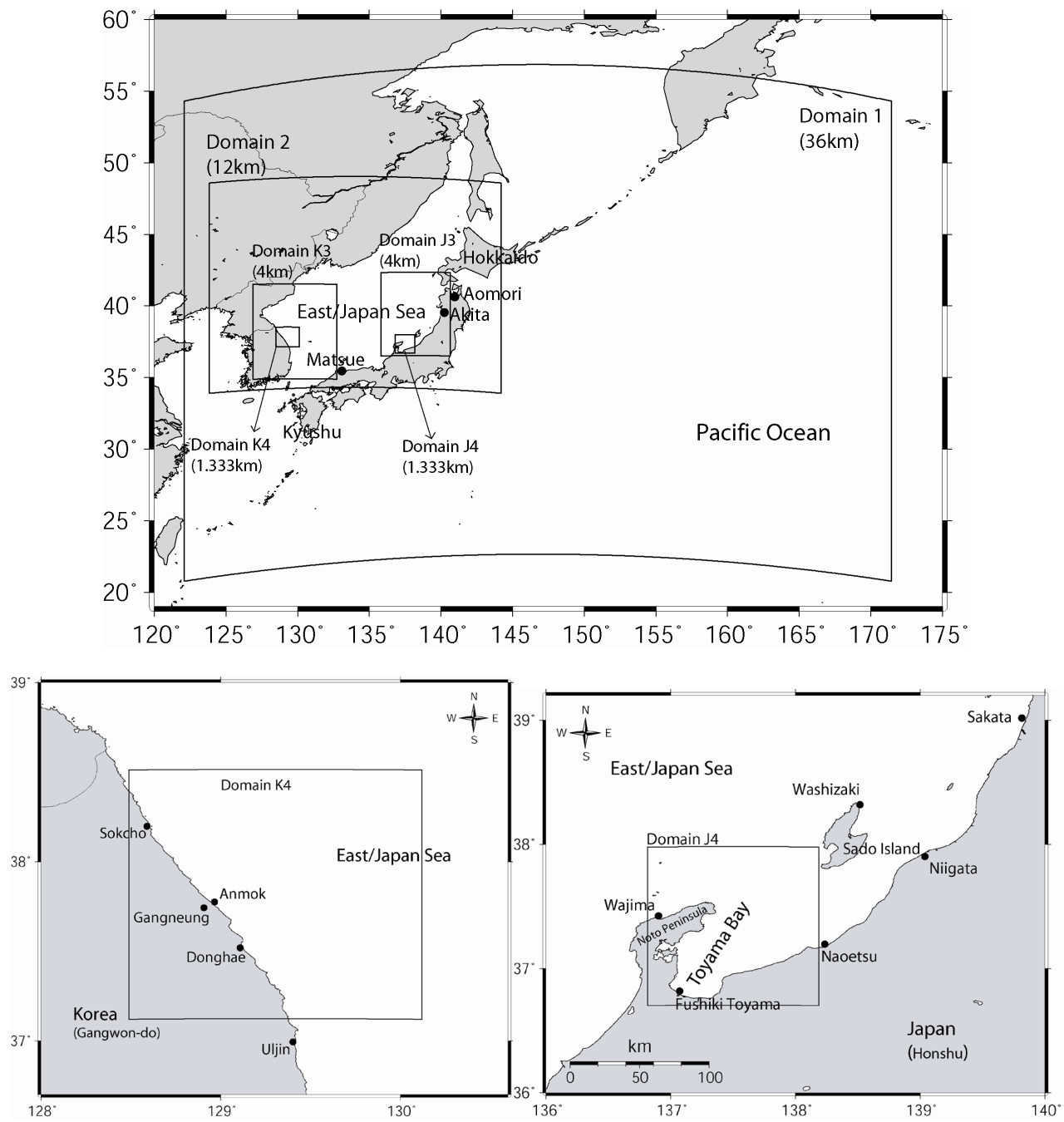

Fig. 7. Computational domains of meteorological and wave models for the events of February 1991 and February 2008 and locations of wave and weather observation stations along the coasts of Korea and Japan. In the event of February 1991, only the domains 1, 2, J3 and J4 were used while all domains including K3 and K4 were used for the event of February 2008.

The water depths for wave modelling were taken from a general bathymetric chart of the oceans (Monahan, 2008) for domain 1, 1 min regional digital bathymetry (Choi et al., 2002) for domain 2 and Japan Oceanographic Data Center (JODC) bathymetry for domains 3 and 4 .

\subsubsection{Simulation results}

The calculated wind fields using the JRA-25 dataset for initial and boundary conditions every twelve hours from 09:00:00 UTC 15 February to 21:00:00 UTC 16 February 1991 are shown in Fig. 8. The low pressure generated off west Kyushu was located west of Honshu, Japan, and was moving to the northeast at 09:00:00 UTC 15 February 1991. The low pressure continued to move northeast and was positioned east of Aomori with strong winds over the EJS at 09:00:00 UTC 16 February 1991, as shown in Fig. 8. While the developed low pressure maintained a quasi-stationary state east of Aomori, starting from noon of 16 February the strong winds of about $20 \mathrm{~m} / \mathrm{s}$ in the north and northeast direction continued for more than a day. These wind field results agreed well with the weather charts during the simulations.

The spatial distributions of calculated maximum significant wave heights using the JRA-25 dataset for initial and boundary conditions are presented during the simulation period from all domains in Fig. 9. The growth of surface waves in the EJS is rather limited since it is a semi-enclosed water mass; this is indicated in the results from domains 1 and 2 . The contour of $5 \mathrm{~m}$ significant wave height extended to the east coast of Korea. The barrier effect of Sado Island and the bathymetric effects at Toyama Bay can also be seen in the spatial distributions of significant wave heights of domains 3 and 4. 

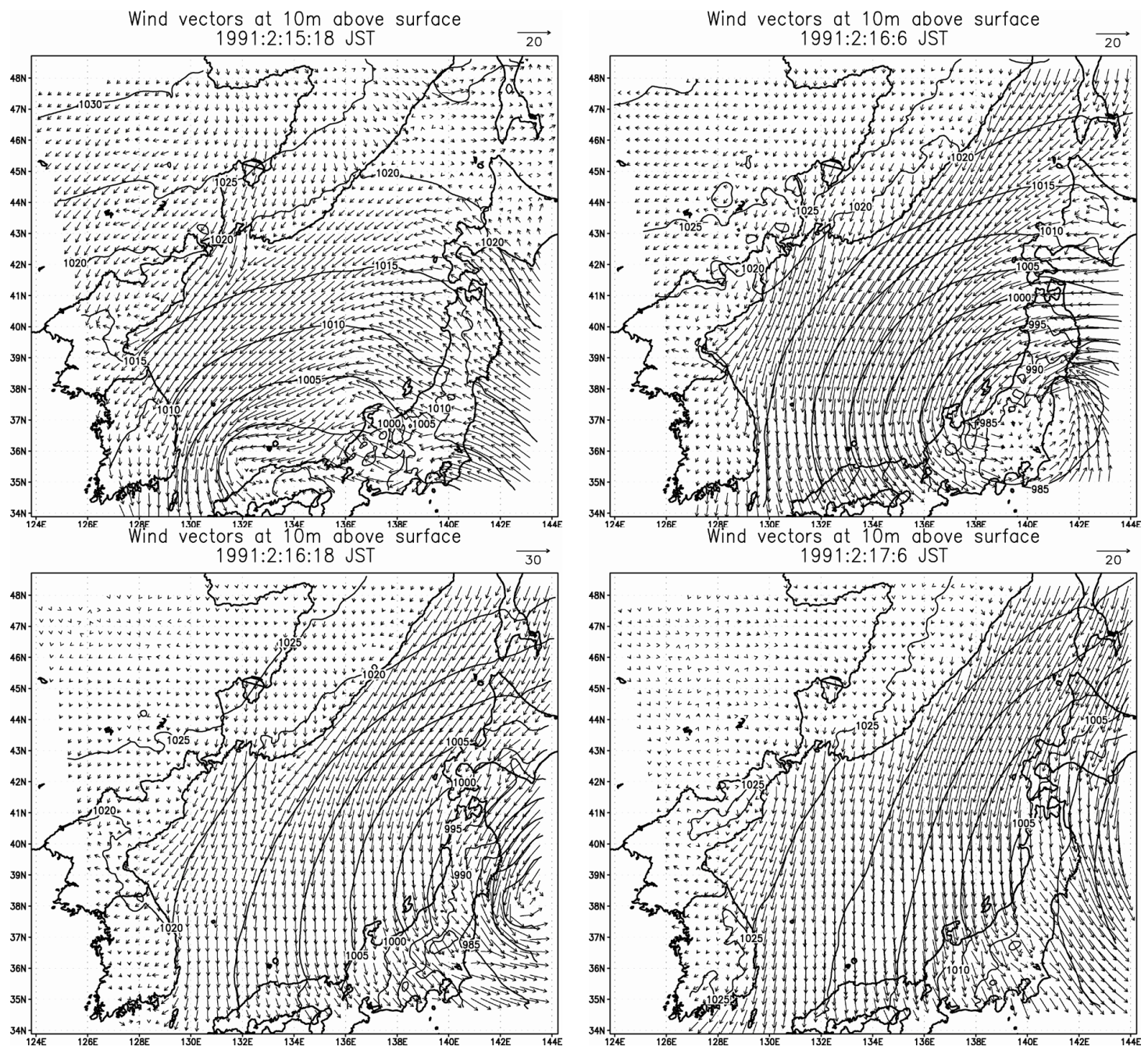

Fig. 8. Calculated wind vectors and isobars from domain 2 for twelve hour increments from 09:00 UTC 15 February to 21:00 UTC 16 February 1991 using JRA-25 for initial and boundary conditions of MM5.

Calculated significant wave heights and periods using the ERA40, JRA-25, and NCEP NCAR datasets at Fushiki Toyama, Naoetsu, Wajima, and Sakata are presented at Fig. 10. The calculated results at Wajima and Sakata only are compared with the available observations. From all locations, the results using the ERA40 dataset showed the largest values for significant wave periods with sharp increase, while the results using the JRA-25 dataset depicted rather small values for wave periods with mild gradients. The results with the JRA-25 dataset also show the smallest values for significant wave heights at all locations. At Wajima and Sakata, the results in wave periods using the JRA-25 dataset showed better agreement with the observations than the other results. In significant wave heights, the results with JRA-25 showed better agreement with the observations than the other results at Sakata, while those at Wajima were somewhat underestimated during the peak of observed significant wave heights from 04:00:00 UTC 16 to 04:00:00 UTC 17 February 1991 compared to the observations.

\subsection{Event in February 2008}

\subsubsection{Data}

The weather charts showing the meteorological conditions from 12:00:00 UTC 22 February to 00:00:00 UTC 24 February 2008 are presented in Fig. 11. The figure shows that a low-pressure system was generated west of the Korean Peninsula over the Yellow Sea at 06:00:00 UTC 22 February and moved rapidly toward the east at 12:00:00 UTC 22 February. Afterwards, it continued to move eastward slowly over the EJS, strengthening in central pressure from $1008 \mathrm{hPa}$ to $992 \mathrm{hPa}$ within $12 \mathrm{~h}$. For a day, from 00:00:00 UTC 23 February to 00:00:00 UTC 24 February, the system stayed near Hokkaido and strengthened 

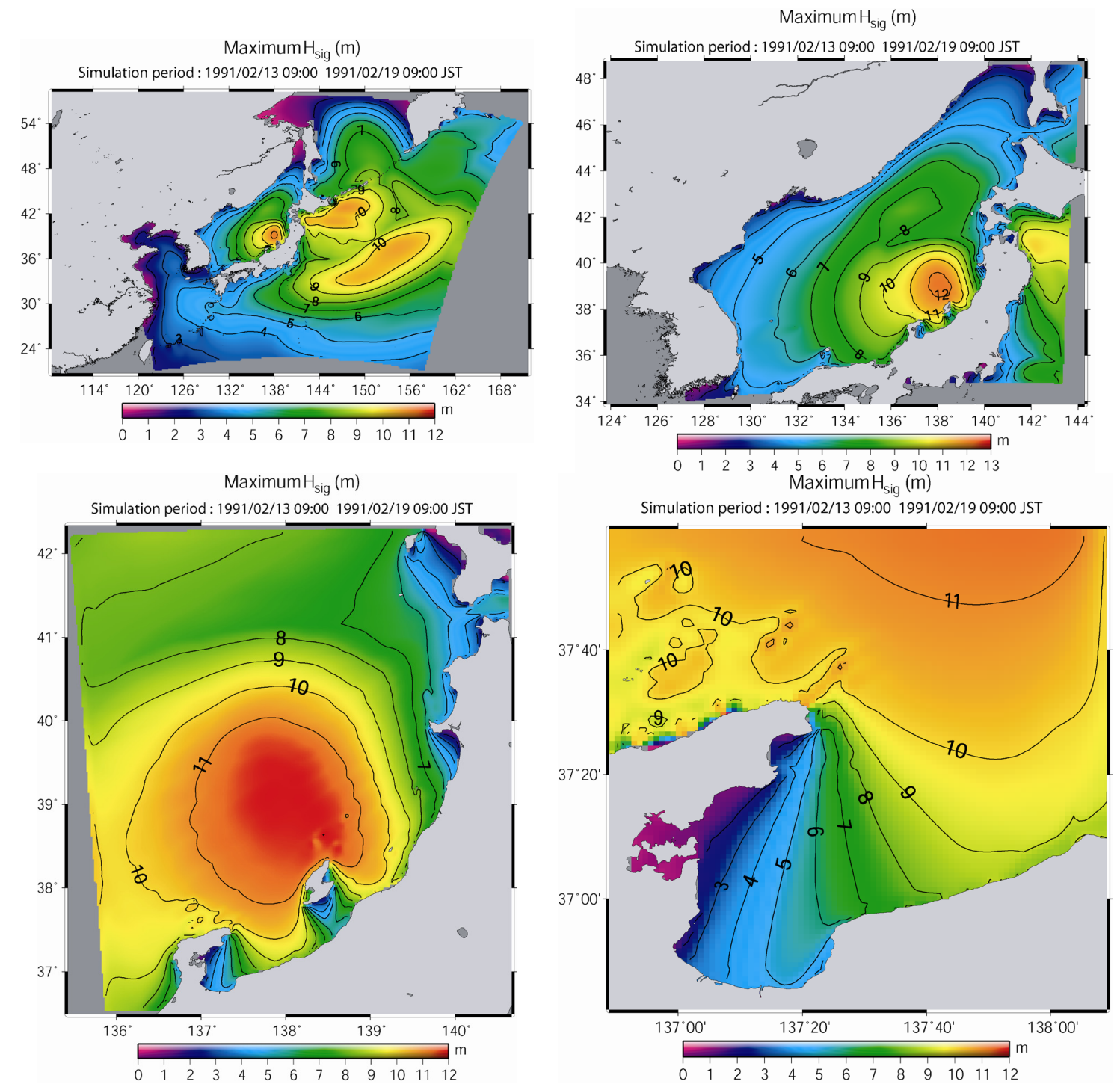

Fig. 9. Distribution of calculated maximum significant wave heights for domain 1, 2, 3, and 4 for the event of February 1991 using JRA-25 for initial and boundary conditions of MM5.

further. Another low-pressure system also developed southeast of Honshu and moved northeastward until it neared the other low-pressure system. Due to these meteorological conditions, westerly and northwesterly winds were dominant during the slow movement of low pressure over the EJS on 22 February while strong north and northeasterly winds of around $20 \mathrm{~m} / \mathrm{s}$ were blowing dominantly on 23 and 24 February. The observed winds from JMA Automated Meteorological Data Acquisition System (AMEDAS) at Washizaki, Sado Island, were $18 \mathrm{~m} / \mathrm{s}$ in a northwest direction at 13:30:00 UTC 23 February and $20 \mathrm{~m} / \mathrm{s}$ in the same direction at 20:40:00 UTC 23 February. The observed wind at Fushiki, Toyama, was $7.6 \mathrm{~m} / \mathrm{s}$ in the northwest direction and $6 \mathrm{~m} / \mathrm{s}$ in the north direction at 12:00:00 UTC 23 February and at 09:00:00 UTC 24 February, respectively. Therefore, we determined that the high waves that caused the coastal damage in Toyama Bay were not under the influence of strong winds.

The observed wave characteristics are presented in Table 1 . The maximum values of wave height and period at Naoetsu were observed at 10:00:00 UTC 23 February, whereas those at Toyama, Fushiki Toyama, and Wajima were observed in the afternoon on 24 February. Moreover, the observed maximum value of wave period at Naoetsu was smaller than the others. From the meteorological conditions and wave observations, it can be determined that the peak values of the wave characteristics at Naoetsu were due to high waves caused by the slowly moving low pressure through the EJS, while the values at the other locations were due to the swell caused by the quasi-stationary low-pressure 

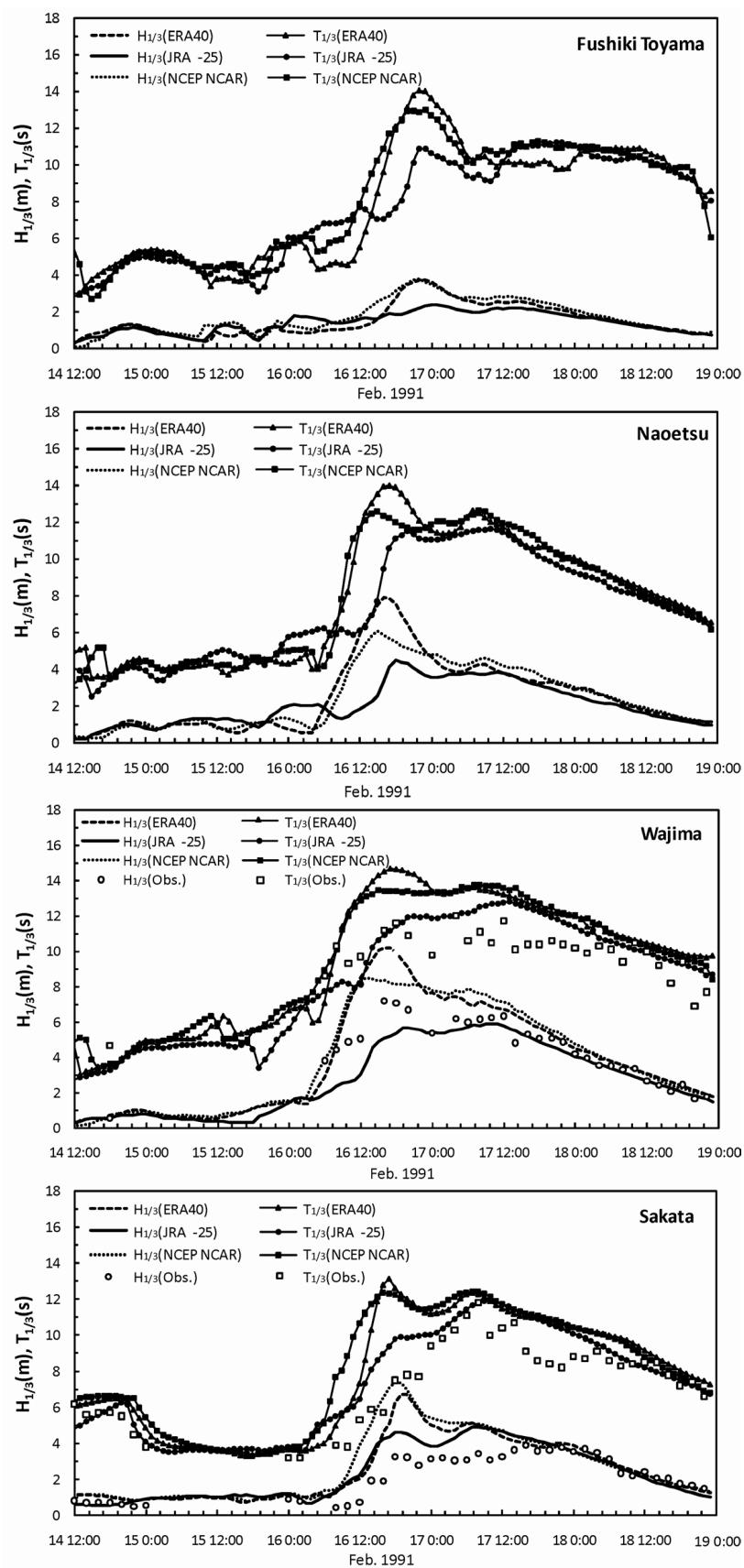

Fig. 10. Comparisons of observations and calculations of wave characteristics at Fushiki Toyama, Naoetsu, Wajima, and Sakata in Japan for the event of February 1991. The observations were available only from Wajima and Sakata.

systems east of Hokkaido. Sado Island also played a role as a barrier against the swell that was propagating towards Naoetsu. The observed maximum values of wave height and wave period at Anmok in the central east coast of Korea were $5.5 \mathrm{~m}$ and $14.17 \mathrm{~s}$ at 11:00:00 UTC 24 February 2008. These waves were also due to the swell caused by the quasistationary low-pressure systems.

\subsubsection{Model set-up}

Figure 7 shows the computational domains for the meteorological and wave models. Four level nesting was performed throughout the simulations with grid intervals of $36 \mathrm{~km}, 12 \mathrm{~km}, 4 \mathrm{~km}$, and $1.333 \mathrm{~km}$ for each domain. The domains 1, 2, J3 and J4 were the same as the domains used in the simulation for February 1991, with domains 1 and 2 covering the EJS and parts of the northwest Pacific Ocean. In this case, two more domains were added to the case of 1991 to cover the east coast of Korea including Anmok, Gangwon-do (Fig. 7), where abnormal storm waves were observed. The simulation was carried out over a period of $78 \mathrm{~h}$ from 00:00:00 UTC 22 February to 06:00:00 UTC 25 February 2008 . The initial condition and lateral and surface boundary conditions for the meteorological model were imposed every six hours from NCEP FNL (Final) Operational Global Analysis data (Table 2). FDDA was also applied to the first domain in wind, temperature and mixing ratio fields every six hours with NCEP FNL data. The water depths of wave modelling for domains $1,2, \mathrm{~J} 3$, and $\mathrm{J} 4$ were the same as those of the 1991 case, while the water depths for domain K3 and K4 were taken from the 1 min regional digital bathymetry (Choi et al., 2002).

\subsubsection{Simulation results}

The calculated wind vectors from domain 2 were recorded every six hours from 21:00:00 UTC 22 February to 15:00:00 UTC 23 February 2008 are shown in Fig. 12. Counterclockwise wind vectors are clearly presented in the figure at 21:00:00 UTC 22 and 03:00:00 UTC 23 February as the low-pressure area moved eastward. The winds strengthened as the low pressure neared Aomori and joined the other developed low pressure. After the low pressure passed over the EJS, the strong north and northwesterly winds were predominant; these calculated wind patterns agree well with the weather charts in Fig. 11. The calculated wind speeds and directions were compared with observations at Matsue, $\mathrm{Ni}$ igata, Sakata, and Akita from JMA AMEDAS (see Fig. 7 for their locations). These four stations are located along the Japanese coast on the EJS side. The calculated wind speeds and directions showed good accordance with the observations, while the estimated wind speed at Niigata was a bit higher than the observation (see Fig. 13).

The results in Fig. 14 are similar to those shown in Fig. 9 in terms of characteristics of surface wave growth in the EJS from domains 1 and 2 and the barrier effect of Sado Island and the bathymetric effects at Toyama Bay from domains 3 and 4.

The comparisons of significant wave height and period at Wajima, Sakata, Naoetsu, and Fushiki Toyama are shown in Fig. 15. The simulation results show good agreement with observations. The stations facing the EJS in the west or northwest direction such as Wajima, Sakata, and Naoetsu 
(a)

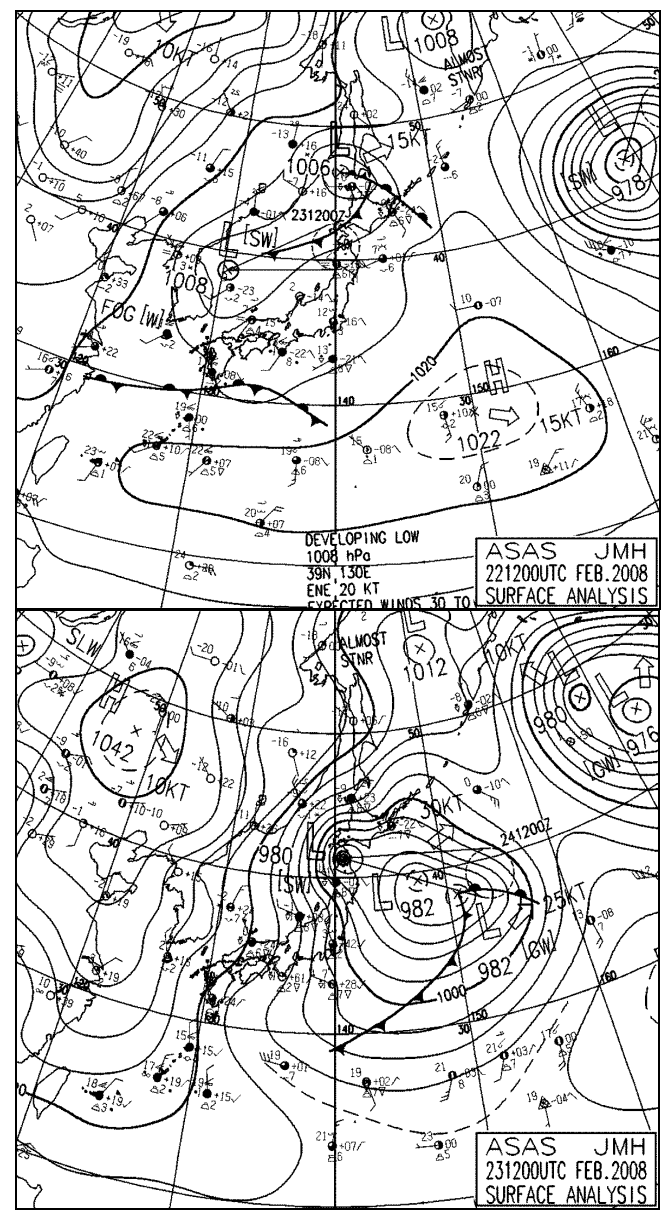

(b)

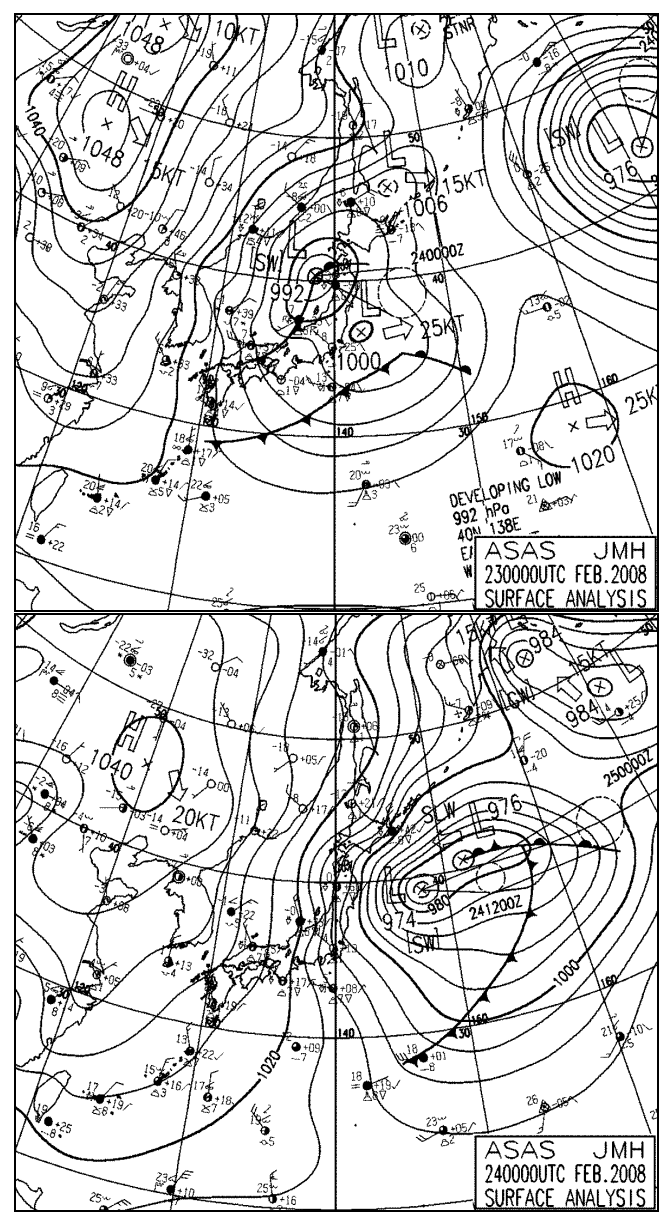

Fig. 11. Weather charts for twelve hour increments from 12:00 UTC 22 February to 00:00 UTC 24 February 2008 (from JMA).

were under the influence of developed wind waves from the west or northwest direction due to the moving low pressure and swell from the north and northeast due to the sequential quasi-stationary low-pressure systems occurring from around noontime on 23 February. The Fushiki Toyama station was affected only by the swell propagated from north and northeast direction due to the Noto Peninsula (Fig. 7).

The simulation results at Anmok, Korea, show good agreement with observations of significant wave height, as shown in Fig. 16. However, the corresponding wave period was somewhat underestimated in the simulation. Due to the movement of the low-pressure area eastward from the Korean Peninsula, Anmok station was under the influence of developed wind waves beginning early in the morning on 23 February, and these high waves continued for more than two days due to the ensuing swell after the developed wind waves.

In Figs. 17 and 18, the two-dimensional wave spectra at Fushiki Toyama and Anmok are presented for 6-h and 12-h periods respectively during the simulation. Wave energy has a wide range of frequencies and directions, whereas swell en- ergy is distributed over a narrow range of frequencies and directions. It is important to note that wave direction is shown in terms of propagating away from the grid point; in other words, it propagates toward the edge of the plot, following the oceanographic convention, which is contrary to the atmospheric convention for wind direction.

In Fig. 17, at 05:00:00 UTC 23 February, the relatively young wind waves with a period of 4 to $5 \mathrm{~s}$ dominate due to the slow-moving low pressure from the north to northeast direction. Then a relatively young swell appeared that was moving in the north-east-north direction at 11:00:00 UTC 23 February, but the wind waves were still dominant in wave energy. Six hours later, the swell was more developed and became dominant, but still the wind waves coexisted with the swell at 17:00:00 UTC 23 February. The double-peaked frequency spectrum in the northeast direction became a onepeak spectrum with a dominant swell in the northeast at 23:00:00 UTC 23 February, and the energy of wind waves disappeared. Subsequently, the wave energy in a narrow frequency band in the northeast direction caused by the developed swell from the quasi-stationary low-pressure systems 

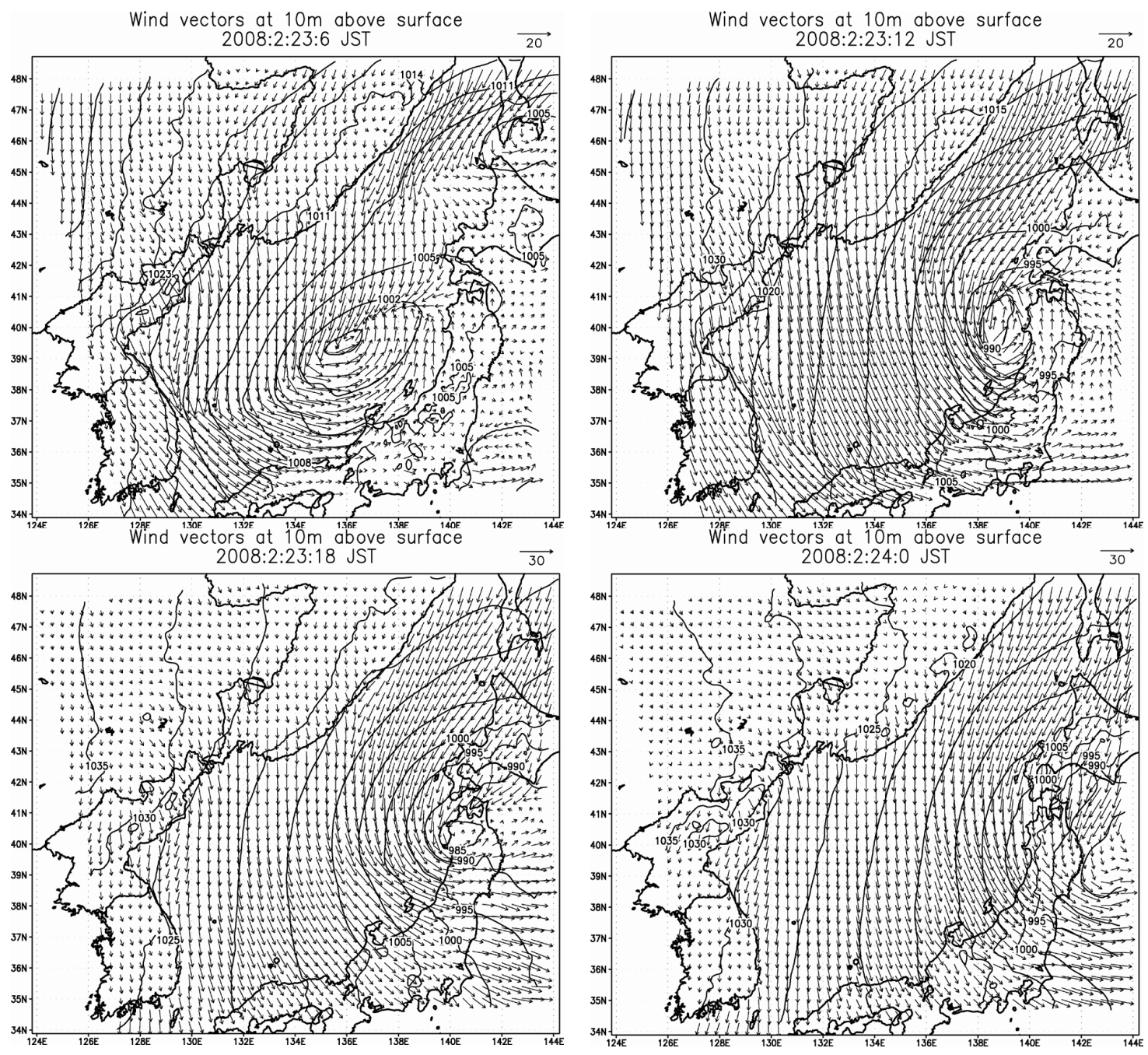

Fig. 12. Calculated wind vectors and isobars from domain 2 for six hour increments from 21:00 UTC 22 February to 15:00 UTC 23 February 2008 .

occupied the spectral plots, even though the winds became weak in a different direction from 07:00:00 UTC 24 February at Fushiki Toyama, as shown in Fig. 17.

At Anmok, Korea, the wave energy group in the top right at 21:00:00 UTC 22 February due to wind waves caused by moving the dominating low pressure, and the dominant period was about 7 to $8 \mathrm{~s}$. Then the wind waves became more developed with a dominant period of around $10 \mathrm{~s}$, showing the wave energy in a wide range of frequency and direction until 21:00:00 UTC 23 February. The dominant wave energy, then, became narrow in frequency at 09:00:00 UTC 24 February due to the incoming swell, even though the wave energy still varied in direction due to the open location of a wave measurement instrument at Anmok. When the local wind was very weak, the high wave energy due to the swell existed in the northeast direction, showing that the dominant wave energy became narrow in both frequency and direc- tion at 21:00:00 UTC 24 February. Because the wave periods were somewhat underestimated in simulation at Anmok, the frequency spectrum from observed data is expected to be more centre-biased than the calculated one.

\section{Discussion}

Since the main reason for abnormal storm waves in the EJS is the wind field input due to low pressures in winter, we classified three patterns of meteorological conditions for the generation process based on the literature reviews mentioned in Sect. 1, which dealt with various events of abnormal storm waves in the EJS and the numerical simulations performed in this study.

First, an area of low pressure developed over the continent of East Asia or near the Korean Peninsula strengthens while moving toward the east over the EJS, and then it 

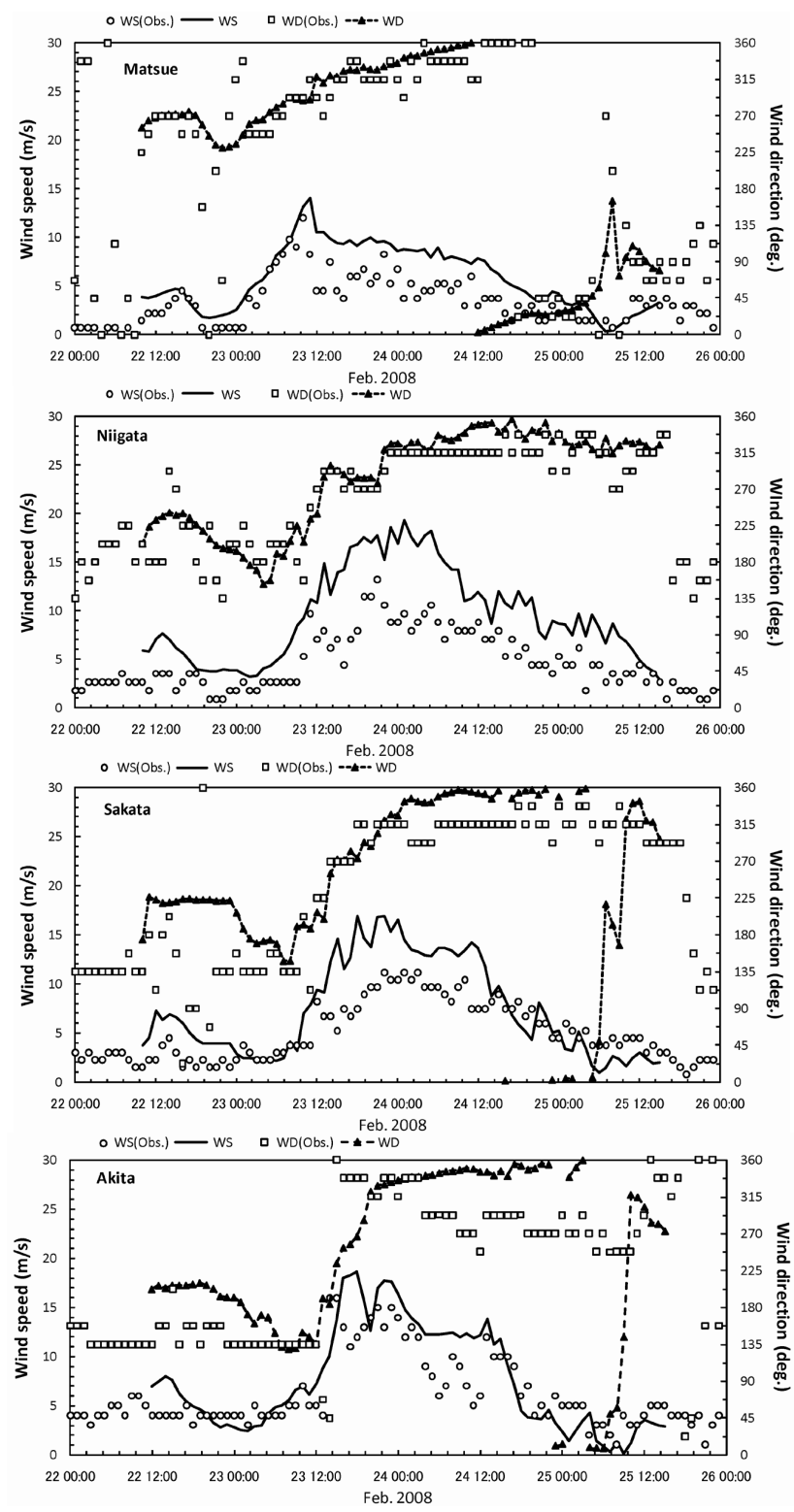

Fig. 13. Comparisons of observations and calculations of winds at Matsue, Niigata, Sakata and Akita in Japan for the event of February 2008 .

becomes a quasi-stationary low-pressure system east of or near Hokkaido, Japan. Under this condition, the wind waves caused by the moving low pressure are followed by the swell resulting from the quasi-stationary state of the low pressure. The abnormal storm waves in December 2003 and February 2008 were examples of this pattern.

Second, an area of low pressure develops in East China Sea or south of Honshu, the main island of Japan, moves northeast or north to near Hokkaido, and then becomes a quasi-stationary low-pressure system causing the swell in the EJS. The abnormal storm waves in February 1991 were an example of this second pattern.
Third, a low-pressure system generated over the continent of East Asia or near the Korean Peninsula moves southeastward over the EJS and the Japanese islands or becomes weak and disappears in the EJS. The abnormal storm waves in October 2006 were in this third category (see Fig. 19 for meteorological conditions of a slowly moving low pressure toward the southeast). In this kind of meteorological pattern, the east coast of Korea is under the strong influence of wind waves. Kim and Lee (2008) reported details of the event in October 2006.

In any of the conditions above, it is important to note that there was another second low-pressure system that was generated and developed in the Pacific Ocean. This second lowpressure system caused the quasi-stationary state of the lowpressure system from the EJS by somehow blocking eastward movement as a part of the wintertime meteorological conditions over East Asia and the northwest Pacific. Therefore, it is desirable to consider all these meteorological conditions in meteorological modelling to account for the external forces on surface waves in wave modelling. The moving speed of low-pressure systems and the sea surface temperature are also important factors that decide the intensity of wind fields caused by low pressure, similar to storm waves created by tropical cyclones. Table 4 shows the classification of past events based on the above three patterns of meteorological conditions. The term "Unknown" in the pattern column indicates that no data is available to determine the pattern, while the mark, ${ }^{*}$, indicate a guess based on available data in Table 4.

Although the bogussing scheme is a very effective method to resolve and describe the developed low-pressure systems in this study, care should be taken when applying it to a low-pressure system. Because the horizontal wind profile in the bogussing scheme is produced by the Rankine vortex, the radii of maximum wind $\left(R_{\mathrm{m}}\right)$ and maximum wind speed $\left(V_{\max }\right)$ are essential information to include on the vortex wind profile (see Eq. A2). However, the $R_{\mathrm{m}}$ is not normally available even for low-pressure systems on weather charts. Therefore, this information is assumed based on available information of tropical storms of a similar scale. Moreover, due to the grid intervals of the computational domains of the meteorological model, the $R_{\mathrm{m}}$ is inevitably pre-determined. Hence, it is difficult to apply these data in wave forecasting.

\section{Summary and conclusions}

In this study we described the results of long-term continuous researches on the abnormal storm waves caused by developed low pressures evolving and moving over the EJS in winter. It focuses on the generation process and hindcast based on literature review and numerical modelling using an atmosphere-wave modelling system. The simulations were performed for three recorded events of abnormal storm waves in the order of the events in 2003, 1991 and 2008. In 

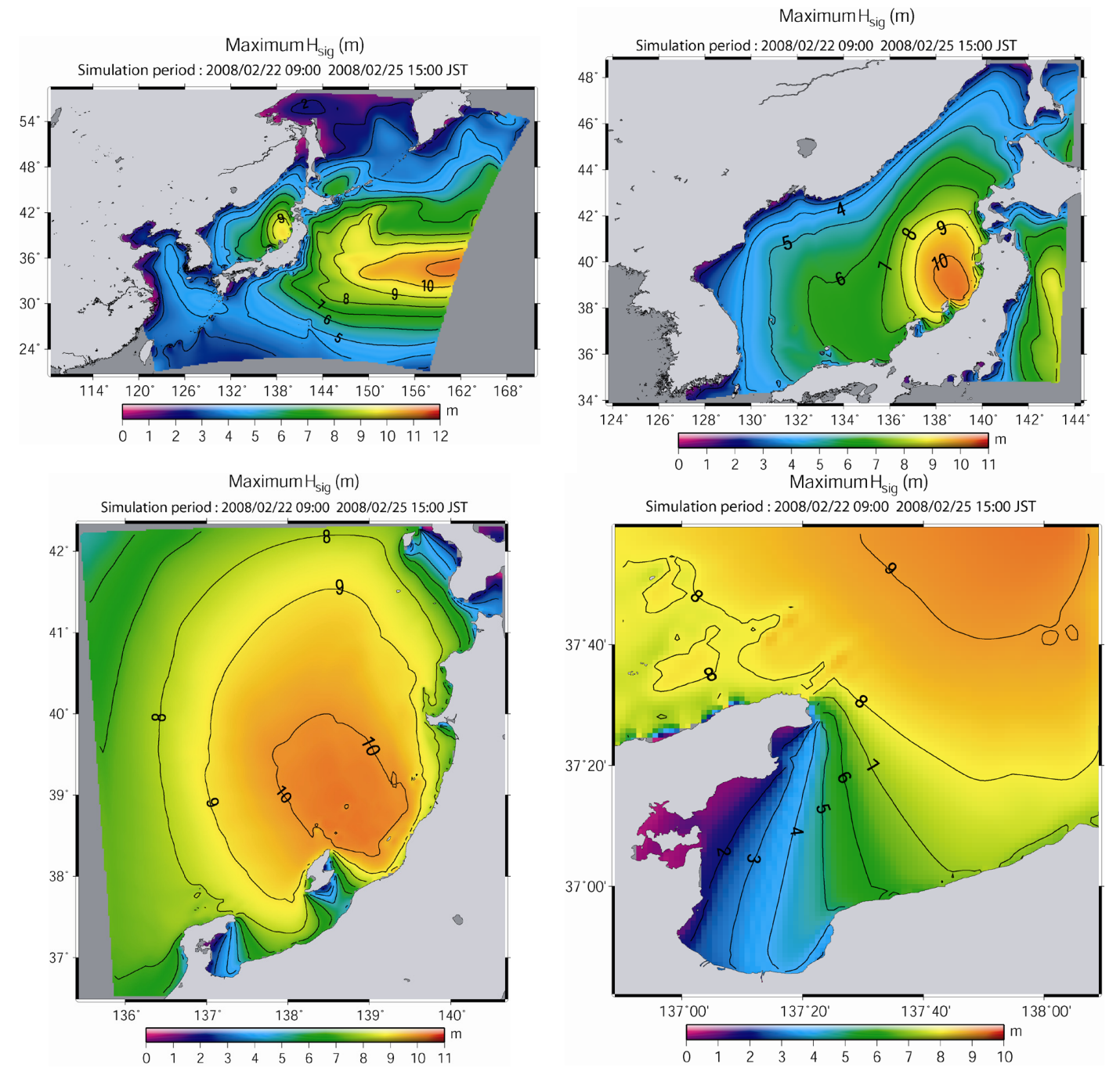

Fig. 14. Distribution of calculated maximum significant wave heights for domains 1, 2, 3, and 4 for the event of February 2008.

Table 4. Classification of past events in terms of meteorological conditions.

\begin{tabular}{llll}
\hline Date & $\begin{array}{l}\text { Patterns based on the } \\
\text { track of low pressure }\end{array}$ & Related coastal damages & Reference \\
\hline 2 January 1929 & Pattern 2 & Toyama Bay, Japan & Kitaide (1952) \\
9 December 1943 & Pattern 1 & Toyama Bay, Japan & Kitaide (1952) \\
16 February 1949 & Pattern 2 & Toyama Bay, Japan & Kitaide (1952) \\
6 January 1963 & Pattern 1* & Toyama Bay, Japan & Isozaki and Yoshio (1972) \\
31 December 1965 & Unknown & Toyama Bay, Japan & Isozaki and Yoshio (1972) \\
23 February 1966 & Pattern 2 & Toyama Bay, Japan & Isozaki (1971) \\
28 October 1967 & Pattern 2 (Typhoon) & Toyama Bay, Japan & Isozaki and Yoshio (1972) \\
31 January 1970 & Pattern 2 & Toyama Bay, Japan & Isozaki and Yoshio (1972) \\
28 December 1976 & Pattern 2 & Toyama Bay, Japan & Hatada and Yamaguchi (1998) \\
26 October 1976 & Pattern 1 & Dae Wha Bank in the EJS & Choi and Joung (1979) \\
2 January 1981 & Pattern 1 & & Joung et al. (1984) \\
16 January 1984 & Unknown & Toyama Bay, Japan & Yoshida et al. (1985) \\
16 February 1991 & Pattern 2 & Toyama Bay, Japan & This study \\
20 December 2003 & Pattern 1 & Toyama Bay, Japan & This study \\
23 October 2005 & Pattern 1 & East coast of Korea & Kim and Lee (2008) \\
12 October 2006 & Pattern 3 & East coast of Korea & Jeong et al. (2007) and Kim and Lee (2008) \\
23 February 2008 & Pattern 1 & Anmok, Korean and Toayama Bay, Japan & Lee et al. (2008) \\
\hline
\end{tabular}

* indicates a guess based on available data 

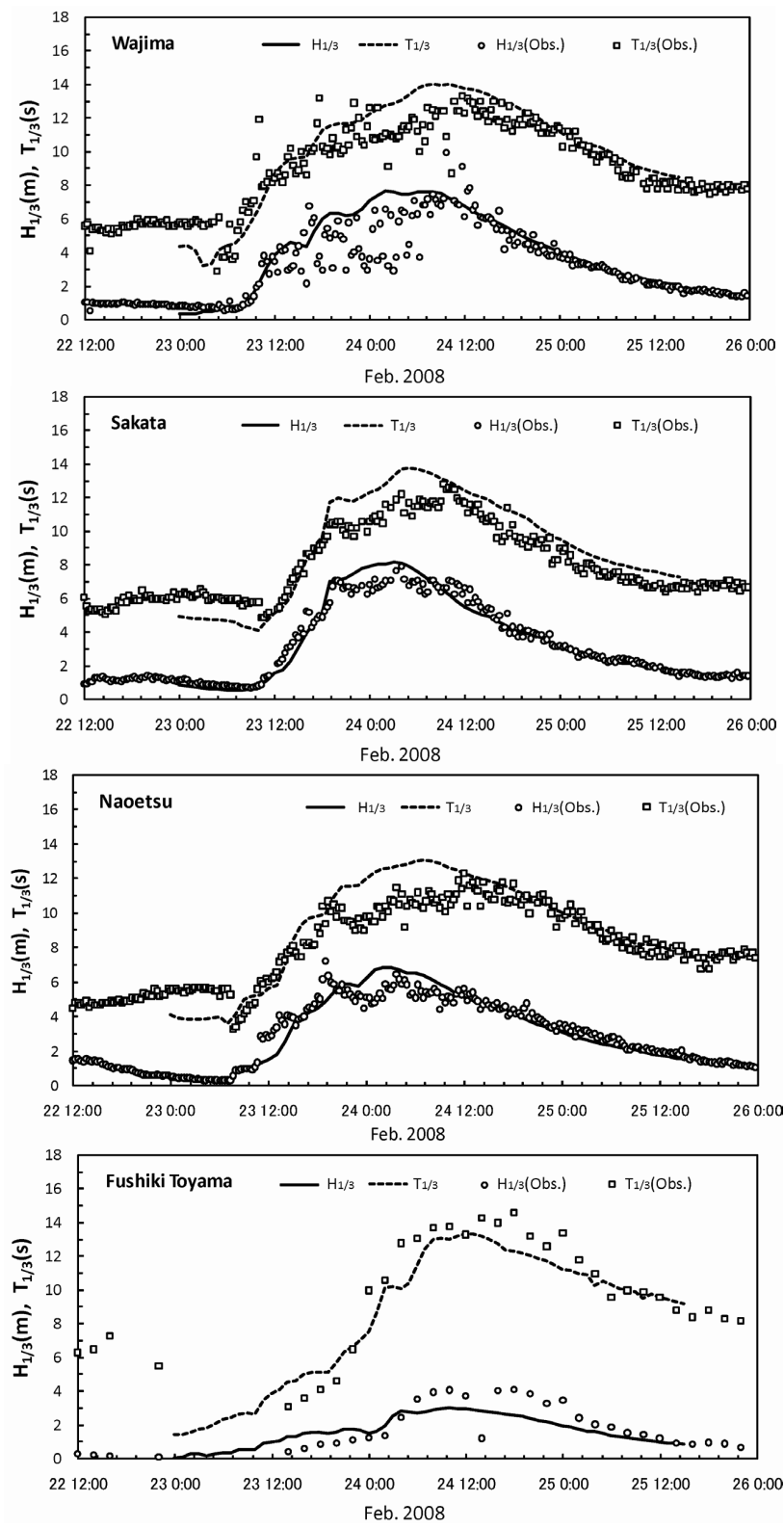

Fig. 15. Comparisons of observations and calculations of wave characteristics at Wajima, Sakata, Naoetsu and Fushiki Toyama in Japan for the event of February 2008.

the case of 2003 event, one of the objectives of the study was to evaluate the applicability of bogussing scheme to extratropical cyclones with available GSM data in addition to the investigation of the generation process of abnormal storm waves. In the case of 1991, the objective was to compare the freely available dataset (ECMWF ERA40, NCEP NCAR data, and JMA JRA-25) for wave modelling in addition to the original purpose. NCEP FNL dataset is not available for the year of 1991. In the case of 2008, the NCEP FNL dataset was chosen for the simulation of the abnormal storm waves.

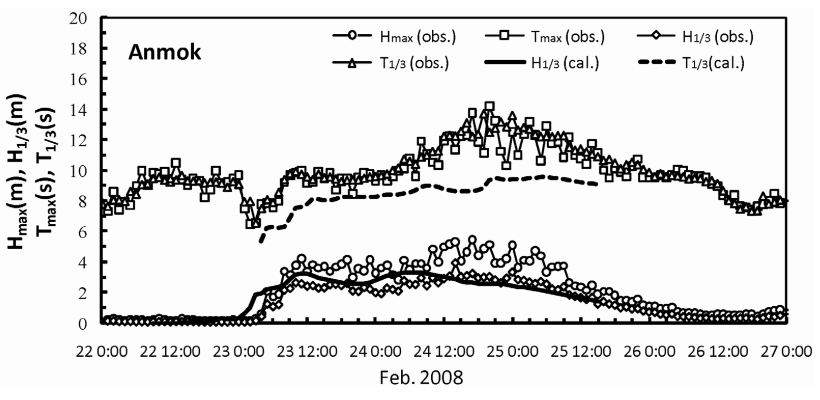

Fig. 16. Comparisons of observations and calculations of wave characteristics at Anmok in Korea for the event of February 2008.

The performance of the numerical simulations of a meteorological model when using a bogussing scheme was improved for both the resolved low-pressure system and surface wind field $\left(U_{10}\right)$ in the events of December 2003 with respect to those from the GSM of JMA GPV and the model run without a bogussing scheme. The abnormal storm waves recorded at Naoetsu Harbour and OWO on 20 December in 2003 were reproduced by the modelling system, deriving simulation results that were close to the observed values of a significant wave height of $9.24 \mathrm{~m}$ and significant wave period of $12.9 \mathrm{~s}$.

In addition to the bogussing scheme to improve meteorological modelling, three kinds of available global datasets, ERA40, JRA-25, and NCEP NCAR, were used for background data of the meteorological model to investigate the characteristics and effect of the grid resolution of the dataset. In comparison with available wave observations at Wajima and Sakata, Japan, the results with JRA-25 showed closer agreement with observations. The grid resolution of JRA-25 $(1.25 \mathrm{deg})$ may be the main reason for the results, since the horizontal wind profile by the bogussing scheme is somewhat pre-determined by the grid resolution of background data and computational domains. In the case of the February 2008 event, the calculated wind and wave field were compared with observations and showed good agreement. The swell components in surface waves were clearly identified from wave spectral plots at Anmok and Fushiki Toyama.

The meteorological conditions that cause abnormal storm waves in the EJS are classified into three patterns based on the literature of historical events and numerical modelling. The speed and track of a low-pressure system and the interaction with another pressure system in the East Asia and north Pacific regions are the main factors in the classification, although some important physical parameters are not considered in this study.

In air-sea interaction, the transfer of heat, mass and momentum between air and sea depends on conditions such as sea surface temperature, the temperature difference between air and underlying sea, and wind waves. In particular, the wind waves are considered the most important factor in 


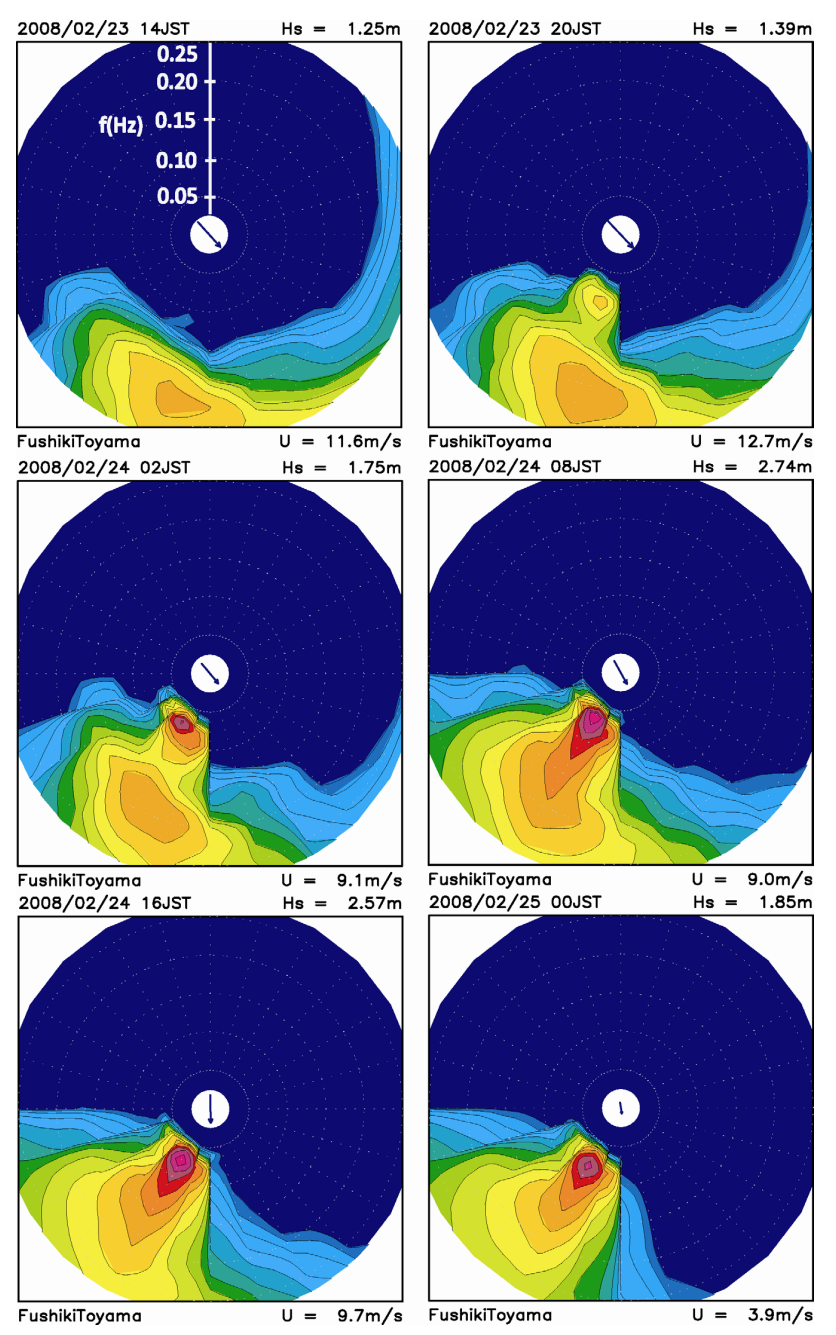

Fig. 17. Calculated 2-D wave spectral plots at Fushiki Toyama, Japan, for the event of February 2008. Time and significant wave height are shown above each panel, while wind speed and direction are shown below and in the centre of each panel, respectively. The 16-level shaded colours represent wave energy density $\left(\mathrm{m}^{2} / \mathrm{Hz}\right)$ being doubled in each level, with dark blue indicating the absence of wave energy (1.61238e-04) and light purple indicating a local maximum (10.56695). Wave direction is toward the edge of the plot.

understanding air-sea interaction. Although air-sea interaction has been a subject of discussion for a long time, the most useful observations covering all wind regimes from weak and mild to very strong ones under tropical cyclones have only recently become available (Edson et al., 2007). In a lowwind regime, turbulence and turbulent mixing have low intensity in the marine atmospheric boundary layer. The surface wave modulation is clearly observable in wind velocities, static pressure and humidity. In moderate winds, turbulence has the dominant influence on water vapour and flow velocities, while the pressure field is organised and coherent with the waves (Hristov, 2005). In high winds such as
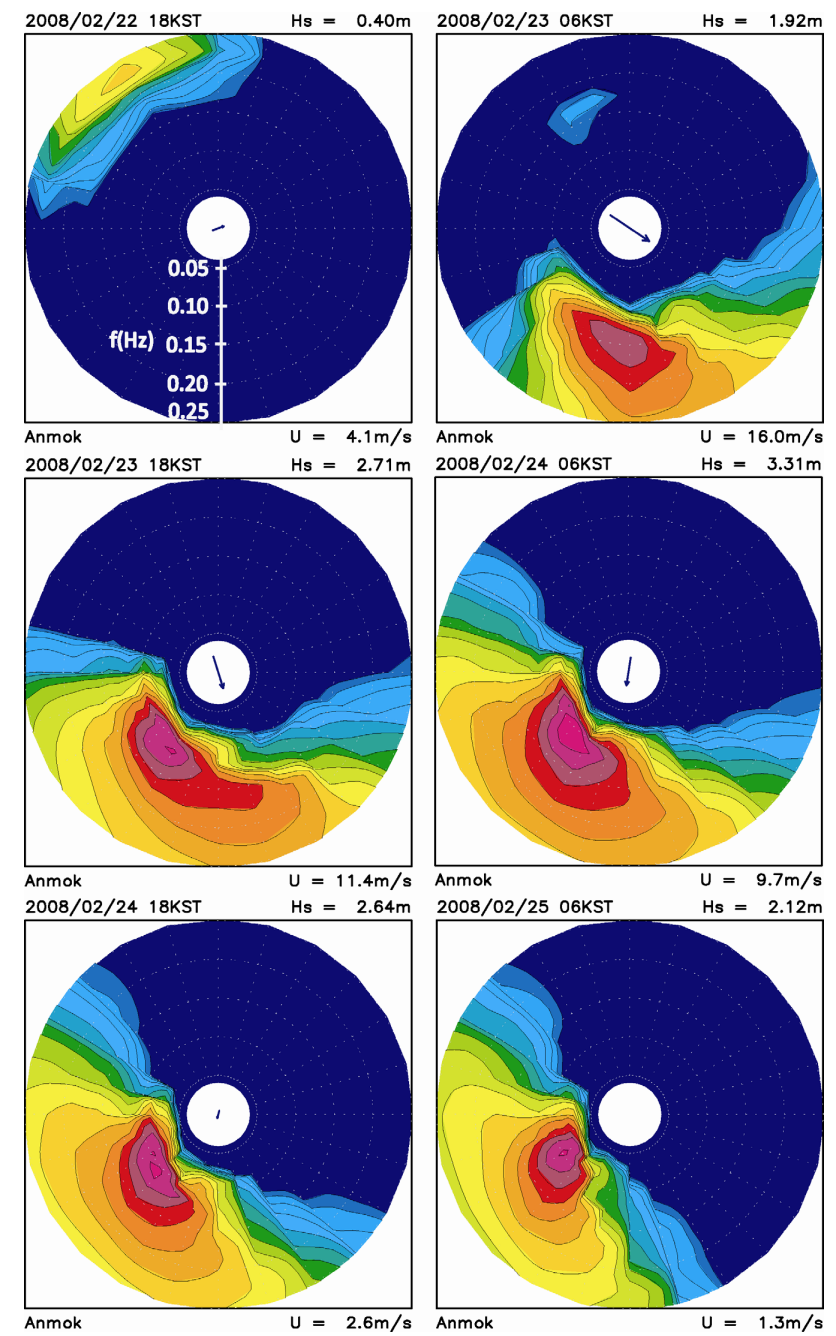

Fig. 18. As in Fig. 17, but at Anmok, Korea.

in tropical cyclones, the interaction processes are influenced by sea spray, spume and air flow separation due to breaking of surface waves (Doyle, 2002). The effect of waves on ocean surface currents and the ocean mixed layer is also a complex phenomenon in air-sea interaction. These effects of surface waves on the marine atmospheric boundary layer, however, are not considered in the atmosphere-wave coupled modelling system in this study and remain a subject and a guide for further study.

Both hindcasting of abnormal storm waves in the EJS and forecasting of wave fields using the atmosphere-wave modelling system are crucial for determining the design of coastal structures and for preventing coastal damage and disaster. 

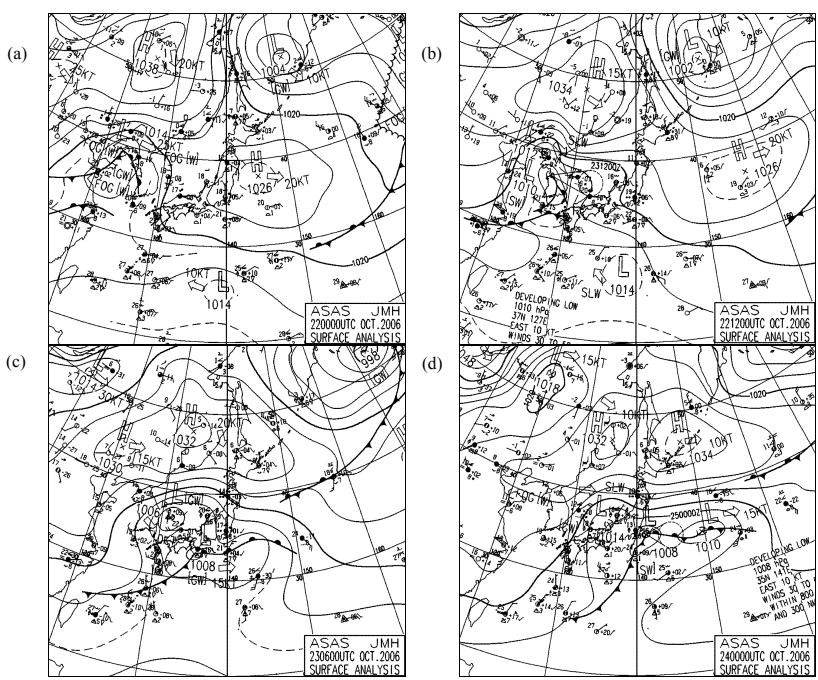

Fig. 19. Weather charts at 00:00 UTC 22, at 12:00 UTC 22, at 06:00 UTC 23 and at 00:00 UTC 24 October 2006 (from JMA).

\section{Appendix A}

The bogussing scheme is performed in two steps in the REGRID process of MM5 as follows.

\section{A1 Detection and removal of cyclones}

1. Searching for the storm centre in first guess within the searching radius (fixed to $400 \mathrm{~km}$ ) according to the given Best Track position.

2. Removal of first guess vortices and divergence within $300 \mathrm{~km}$ of first guess storm and recomputed velocity.

3. Removal of geostrophic vortices within $300 \mathrm{~km}$ of first guess storm and associated geopotential heights.

4. Removal of the temperature anomaly from the hydrostatic relation using calculated geopotential anomaly.

5. Removal of enhanced relative humidity within $600 \mathrm{~km}$ of first guess storm.

6. Specifying bogus storm velocity and stream function centred on Best Track position.

7. Solving of the non-linear balance equation for geopotential heights.

8. Calculation of the bogus temperature from the balanced height field.

9. Modification of relative humidity to be nearly saturated out to a radius of maximum wind $\left(R_{\mathrm{m}}\right)$ and mixing it with the background at $1200 \mathrm{~km}$ radius.

\section{A2 Generation and blending with modified first guess}

The bogus vortex wind profile was generated using the Rankine vortex model below based on several assumptions,

$v=A(z) F(r)$

$F(r)=\left\{\begin{array}{lll}\frac{V_{\max }}{R_{\mathrm{m}}} r & \text { if } & r \leq R_{\mathrm{m}} \\ \frac{V_{\max }}{R_{\mathrm{m}}^{\alpha}} r^{\alpha} & \text { if } & r>R_{\mathrm{m}}\end{array}\right.$

where $\alpha=-0.75$ is a parameter for wind profiles at large radii $\left(r>R_{\mathrm{m}}\right), R_{\mathrm{m}}$ is the maximum radius, and $V_{\max }$ is the maximum tangential wind speed. The assumptions are given as follows:

1. axi-symmetry

2. fixed radius of maximum wind field (discussed in detail in Sect. 5)

3. nearly saturated bogus vortex field

4. mass and wind field in nonlinear balance

5. maximum bogus winds as a pre-determined fraction of maximum winds provided

Because insufficient data are available on asymmetry for tropical cyclones, the bogus vortex is assumed to be axisymmetric; therefore, the simulated maximum wind speed is somewhat lower than the observed maximum wind speed. A new bogus vortex or modified wind profile with respect to the asymmetry of real tropical storms is needed to improve the horizontal wind profile.

Acknowledgements. We thank the anonymous reviewers, whose comments helped us improve the quality of this paper. This study was supported by the Global Environment Leader Education Program for Designing a Low-Carbon Society under the auspices of MEXT Special Coordination Funds for Promotion of Science and Technology in the Graduate School for International Development and Cooperation, Hiroshima University. The second author was supported by Korea Ocean Research \& Development Institute (PE9842H) and Korea Institute of Marine Science \& Technology Promotion (PM55210).

Edited by: A. Mugnai

Reviewed by: three anonymous referees 


\section{References}

Blackadar, A. K.: High-resolution models of the planetary boundary layer, in: Adv. Environ. Sci. Eng., edited by: Pfafflin, I. J. R. and Ziegler, E. N., 1, Gordon and Breach Science Publishers, 50-85, 1979.

Cavaleri, L. and Bertotti, L.: Accuracy of the modelled wind and wave fields in enclosed seas, Tellus A, 56, 167-175, 2004.

Cavaleri, L. and Bertotti, L.: The improvement of modelled wind and wave fields with increasing resolution, Ocean Eng., 33, 553565, 2006.

Chalikov, D.: The parameterization of the wave boundary layer, J. Phys. Oceanogr., 25, 1333-1349, 1995.

Chalikov, D. V. and Belevich, M. Y.: One-dimensional theory of the wave boundary layer, Bound.-Lay. Meteorol., 63, 65-96, 1993.

Choi, B. H., Kim, K. O., and Eum, H. M.: Digital bathymetric and topographic data for neighboring seas of Korea (in Korean with English abstract), J. Korean Society of Coastal and Ocean Engineers, 14, 41-50, 2002.

Choi, H. and Joung, C. H.: A study on the numerical calculation for wind waves generated by extratropical cyclones developed rapidly in the Sea of Japan (in Korean with English abstract), J. Korean Met. Soc., 15, 35-43, 1979.

Doyle, J. D.: Coupled Atmosphere-Ocean Wave Simulations under High Wind Conditions, Mon. Wea. Rev., 130, 3087-3099, 2002.

Edson, J., Crawford, T., Crescenti, J., Farrar, T., Frew, N., Gerbi, G., Helmis, C., Hristov, T., Khelif, D., Jessup, A., Jonsson, H., Li, M., Mahrt, L., McGillis, W., Plueddemann, A., Shen, L., Skyllingstad, E., Stanton, T., Sullivan, P., Sun, J., Trowbridge, J., Vickers, D., Wang, S., Wang, Q., Weller, R., Wilkin, J., Williams, A. J., Yue, D. K. P., and Zappa, C.: The Coupled Boundary Layers and Air-Sea Transfer Experiment in Low Winds, B. Am. Meteorol. Soc. , 88, 341-356, 2007.

Gemmill, W., Katz, B., and Li, X.: Daily Real-Time Global Sea Surface Temperature - High Resolution Analysis at NOAA/NCEP, NOAA/NWS/NCEP/MMAB Office Note Nr. 260, 39, 2007.

Grell, G. A.: Prognostic Evaluation of Assumptions Used by $\mathrm{Cu}-$ mulus Parameterizations, Mon. Wea. Rev., 121, 764-787, 1993.

Grell, G. A., Dudhia, J., and Stauffer, D. R.: A description of the fifth-generation Penn State/NCAR Mesoscale Model (MM5), National Center for Atmospheric Research, NCAR Tech. Note, NCAR/TN-398 + STR, 1995.

Hatada, Y. and Yamaguchi, M.: Preliminary study on a prediction method of large swell-like waves in Toyama Bay 'YorimawariNami' , Memoirs of the Faculty of Eng., Ehime Univ., 17, 261271, 1998 (in Japanese with English abstract).

Hristov, T.: Wave-driven scalar ?elds in marine atmospheric boundary layer, Geophys. Res. Abstr., 7, 02863, 2005.

Isozaki, I.: On the characteristics of coastal waves on the coast of Toyama Bay (Report I) (in Japanese with English abstract), Notes of Cooperative Research for Disaster Prevention, 25, 3$15,1971$.

Isozaki, I. and Yoshio, O.: On the characteristics of coastal waves on the coast of Toyama Bay (Report II), Notes of Cooperative Research for Disaster Prevention, 28, 3-17, 1972 (in Japanese with English abstract).

Jeong, W. M., Oh, S.-H., and Lee, D. Y.: Abnormally high waves on the East Coast, J. Korean Society of Coastal and Ocean Engineers, 19, 295-302, 2007 (in Korean with English abstract).
Joung, C.-H., Kim, S. S., Park, S.-U., Min, K. D., and An, H.-S.: A case study on the extratropical cyclone development on the East Sea (in Korean with English abstract), J. Korean Met. Soc., 20, 1-21, 1984.

Kim, T.-R. and Lee, K.-H.: Examinations on the Wave Hindcasting of the Abnormal Swells in the East Coast, J. Korean Society of Ocean Engineers, 22, 13-19, 2008 (in Korean with English abstract).

Kitaide, M.: On the mechanism and forecasting of the so-called "Yorimawari" Wave, Marine Report of the Central Meteorological Observatory, 2, 125-151, 1952 (in Japanese with English abstract).

Lee, H. S., Yamashita, T., Komaguchi, T., and Mishima, T.: Numerical Simulation of so-called 'Yorimawari-Waves' caused by the Low Pressures on Feb. 2008 Using a Meso-scale Meteorological Model and the Wave Model, Annual Journal of Coastal Engineering (JSCE), 55, 161-165, 2008 (in Japanese with English abstract).

Low-Nam, S. and Davis, C.: Development of a tropical cyclone bogussing scheme for the MM5 system, The Eleventh PSU/NCAR Mesoscale Model User's Workshop, Boulder, Colorado, 130134, 2001.

Mase, H., Yasuda, T., Tracey, T. H., and Tsujio, D.: Forecast and hindcast simulations of wind waves which caused disasters along Toyama Coastas on February 2008 (in Japanese with English abstract), Annual Journal of Coastal Engineering (JSCE), 55, 156160, 2008.

Monahan, D.: Mapping the floor of the entire world ocean: the General Bathymetric Chart of the Oceans, Journal of Ocean Technology, 3, 108 pp., 2008.

Ponce de León, S. and Guedes Soares, C.: Sensitivity of wave model predictions to wind fields in the Western Mediterranean sea, Coast. Eng., 55, 920-929, 2008.

Reisner, J., Rasmussen, R. M., and Bruintjes, R. T.: Explicit forecasting of supercooled liquid water in winter storms using the MM5 mesoscale model, Q. J. Roy. Meteor. Soc., 124, 10711107, 1998.

Stauffer, D. R. and Seaman, N. L.: Use of Four-Dimensional Data Assimilation in a Limited-Area Mesoscale Model. Part I: Experiments with Synoptic-Scale Data, Mon. Wea. Rev., 118, 12501277, 1990.

Tolman, H. L. and Chalikov, D. V.: Source terms in a thirdgeneration wind-wave model, J. Phys. Oceanogr., 26, 24972518, 1996.

Tolman, H. L.: User manual and system documentation of WAVEWATCH-III version 2.22, NOAA/NCEP/MMAB, 139 pp., 2002.

Yamaguchi, M., Hatada, Y., and Nakamura, Y.: Estimation of extreme waves along the coast of the Japan Sea based on wave hindcasting, J. Japan Society for Natural Disaster Science, 13, 173-191, 1994 (in Japanese with English abstract).

Yamashita, T., Mishima, T., and Lee, H. S.: Adaptive measures for coastal preservation with consideration of fluctuation of climate change, Proc. of the 15th Pacific-Asian Marginal Seas (PAMS), Busan, Korea, 314-316, 2009.

Yoshida, S., Ishimori, S., and Kato, M.: On the Study of "Yorimawari Nami" by a Wave Model, Research studies of Toyama Mercantile Marine College, 18, 19-25 1985 (in Japanese with English abstract). 